\title{
Evaluation of Antitumor Potential of an Anti- Glypican-1 Monoclonal Antibody in Preclinical Lung Cancer Models Reveals a Distinct Mechanism of Action
}

\author{
Minghua Li \\ University of South Florida \\ Yanhong Wang \\ University of South Florida \\ Xiaoyang Lin \\ University of South Florida \\ Haiqiang Yang \\ University of South Florida \\ Xiaolin Zhang \\ University of South Florida

\section{Yun Bai} \\ MegaNano Biotech Inc. Tampa \\ Xiankun Li \\ Zheng Zhou \\ Lulu Zhang \\ Zheng Zhou

\section{Feng Cheng} \\ University of South Florida \\ Chuanhai Cao \\ University of South Florida \\ Qingyu Zhou ( $\nabla$ qzhou1@usf.edu ) \\ University of South Florida
}

\section{Research Article}

Keywords: glypican-1, therapeutic monoclonal antibody, non-small cell lung cancer, orthotopic lung tumor models, tumor associated fibroblasts

Posted Date: April 28th, 2021 
DOl: https://doi.org/10.21203/rs.3.rs-452001/v1

License: (c) (1) This work is licensed under a Creative Commons Attribution 4.0 International License. Read Full License 


\title{
Evaluation of Antitumor Potential of an Anti-Glypican-1 Monoclonal Antibody in Preclinical Lung Cancer Models Reveals a Distinct Mechanism of Action
}

\begin{abstract}
Emerging evidence has revealed the distinct role of glypican-1 (GPC1) in mediating cellular signal transduction crucial to tumor progression through its function as a coreceptor/modulator for heparin-binding growth factors. The main objective of this study was to investigate the antitumor effect of a novel mouse anti-human GPC1 monoclonal antibody (antiGPC1 mAb) on non-small cell lung carcinoma (NSCLC) and associated molecular mechanisms. Results of the in vitro study showed that anti-GPC1 mAb profoundly inhibited the anchorageindependent growth of A549 and H460 NSCLC cells and exhibited relatively high cytotoxic activities towards CCD-19Lu lung fibroblasts, A549/CCD-19Lu and H460/CCD-19Lu coculture spheroids. In the transwell indirect co-culture system, anti-GPC1 mAb treatment significantly decreased the expression of phospho-Src (Tyr416), phospho-Akt (Ser473) and $\beta$-catenin in the co-cultured CCD-19Lu lung fibroblasts, and the expression of phospho-MEK (Ser217/221) and phospho-p90RSK (Ser380) in co-cultured A549 cells. When anti-GPC1 mAb was administered to tumor-bearing mice either through tail-vein injection once every 72 hours for 8 doses or through intraperitoneal injection once a week for 3 doses and then once every 10 days for 2 more doses, the inhibitory effect of anti-GPC1 mAb on the growth of orthotopic A549 lung tumors was not statistically significant. Nonetheless, results of Western blot analysis showed significant decrease in the phosphorylation of FGFR1 at Tyr766, Src at Tyr416, ERK at Thr202/Tyr204, RSK at Ser380, GSK3 $\alpha$ at Ser21 and GSK3 $\beta$ at Ser9 in tumor samples obtained from tumor-bearing mice receiving the extended-interval dosing of anti-GPC1 mAb. These data implicate that anti-GPC1 mAb treatment impairs the interaction between tumor cells and tumor associated fibroblasts by attenuating the paracrine FGFR signal transduction. In conclusion, although anti-GPC1 mAb alone is not sufficient to inhibit lung tumor growth in vivo, the relatively potent cytotoxicity of anti-GPC1 $\mathrm{mAb}$ in lung fibroblasts and its potential inhibitory effect on the paracrine FGFR signal transduction warrant further studies on the combined use of this $\mathrm{mAb}$ with targeted therapeutics to improve therapeutic outcomes in lung cancer.
\end{abstract}

Keywords: glypican-1, therapeutic monoclonal antibody, non-small cell lung cancer, orthotopic lung tumor models, tumor associated fibroblasts. 


\section{Evaluation of Antitumor Potential of an Anti-Glypican-1 Monoclonal Antibody in Preclinical Lung Cancer Models Reveals a Distinct Mechanism of Action}

Minghua Li ${ }^{1} \dagger$, Yanhong Wang ${ }^{1} \dagger$, Xiaoyang Lin', Haiqiang Yang ${ }^{1}$, Xiaolin Zhang ${ }^{1}$, Yun Bai $^{2}$, Xiankun $\mathrm{Li}^{3}$, Lulu Zhang ${ }^{3}$, Feng Cheng ${ }^{1}$, Chuanhai Cao ${ }^{1, *} \ddagger$ and Qingyu Zhou ${ }^{1, *} \ddagger$

1 Department of Pharmaceutical Sciences, Taneja College of Pharmacy, University of South Florida, Tampa, Florida, U.S.A.; minghua@usf.edu; yanhongwang@mail.usf.edu; xlin3@usf.edu; haiqiangyang@usf.edu; xiaolin1@usf.edu; fcheng1@usf.edu; ccao@usf.edu; qzhou1@usf.edu.

2 MegaNano Biotech Inc. Tampa, Florida, U.S.A.; ybai@megananobiotech.com

${ }^{3}$ Zhengzhou molecular diagnosis engineering technology research center, Zheng Zhou, P.R. China; Ixk@yhkodia.com; luluzhang@yhkodia.com

* Correspondence: ccao@usf.edu; qzhou1@usf.edu; Tel.: +1-813-396-0742 (C.C.); +1-813974-7081 (Q.Z.)

$\dagger$ These authors share equal contribution.

‡ These authors share equal senior authorship. 


\section{Introduction}

Lung cancer is the second most common cancer among both male and female and the leading cause of cancer-related mortality in the United States ${ }^{1}$. NSCLC accounts for approximately $85 \%$ of all lung cancer cases. Despite therapeutic advances ${ }^{2}$, prognosis of advanced NSCLC (Stage 3B and 4) remains extremely poor, with the median survival time being less than 13 months, indicating a pressing need for new treatment options with novel mechanisms of action for patients with NSCLC.

GPC1 is a member of the glypican family of cell-surface heparan sulphate proteoglycans (HSPGs) bound to cell membranes through a glycosyl-phosphatidylinositol (GPI) anchor ${ }^{3}$. It functions as a co-receptor/modulator for growth factors that are bound to heparin or heparan sulfate, including fibroblast growth factor 2 (FGF2) ${ }^{4,5}$, tumor growth factor $\beta$ (TGF- $\left.\beta\right)^{6}$, hepatocyte growth factor (HGF) ${ }^{7}$, vascular endothelial growth factors (VEGF) ${ }^{8}$, Hedgehogs $(\mathrm{HHs})^{9}$, and members of the Wingless-type protein (Wnt) family of secreted glycoproteins ${ }^{10}$. The modulatory effects of GPC1 on the activities of those growth factors have been linked to the enhanced cell adhesion, migration and lipoprotein metabolism ${ }^{11,12}$.

Given the aberrant GPC1 expression in solid tumors and its unique role in tumor progression, a number of studies have explored the diagnostic and prognostic value of GPC1 in certain tumor types, including pancreatic cancer ${ }^{13,14}$, breast cancer ${ }^{15}$, prostate cancer ${ }^{16}$, colorectal cancer ${ }^{17,18}$, glioblastomas ${ }^{5,19}$, esophageal squamous cell carcinoma (ESCC) ${ }^{20}$ and NSCLC 21,22. Several studies have reported that GPC1-positive circulating exosomes in plasma might serve as a diagnostic marker for cancer detection ${ }^{13,23}$, while some have shown conflicting results ${ }^{24-26}$. The clinicopathological significance and diagnostic role of GPC1 in NSCLC remain obscure. One study showed that the GPC1 protein expression was detected by immunohistochemistry (IHC) in all 33 cases of mesotheliomas and 20 out of 21 cases of lung adenocarcinoma ${ }^{21}$, whereas the IHC result obtained from another study showed that GPC1 was expressed in all 82 cases of epithelioid mesothelioma, but only 3 out of 97 cases of lung adenocarcinoma ${ }^{22}$.

Several studies have examined the potential of GPC1 as a druggable target in the treatment of solid tumors. Stable transfection of MDA-MB-231 and MDA-MB-468 breast cancer cells with a GPC1 antisense construct markedly decreased GPC1 protein levels and the mitogenic response to heparin-binding epidermal growth factor-like growth factor (HB-EGF), FGF2, heregulin $\alpha$, heregulin $\beta$, and HGF ${ }^{15}$. Stable transfection of a full-length GPC1 antisense construct downregulated GPC1 gene expression in Colo-357 pancreatic cancer cells, resulting in decreases in anchorage-dependent and -independent cell growth, TGF- $\beta 1$-induced cell growth inhibition, nuclear translocation of phospho-Smad-2 and activity of PAI-1 promoter ${ }^{27}$. Treatment with $10 \mathrm{mg} / \mathrm{kg}$ of a chicken/mouse chimeric anti-human GPC1 mAb was found to suppress tumor growth via the antibody-dependent cell-mediated cytotoxicity (ADCC) and complement-dependent cytotoxicity (CDC) as well as inhibition of tumor angiogenesis in a GPC1-positive TE14 human ESCC xenograft model and a patient derived tumor xenograft (PDX) model ${ }^{28}$. Overall, it has been demonstrated that reduction of GPC1 activity through molecular or pharmacological interventions results in suppression of growth factor induced tumor cell growth, suggesting the potential of GPC1 as a druggable therapeutic target ${ }^{15,27,28}$.

Monoclonal antibody-based targeted therapy offers many benefits over conventional chemotherapy in terms of dosing frequency, potency, and specificity for the target antigen. In this study, the anti-tumor effect of a novel anti-GPC1 mAb was evaluated in A549 and H460 NSCLC cell lines and CCD-19Lu human lung fibroblasts using a variety of 2D and 3D monoculture and co-culture models and an orthotopic A549 lung tumor xenograft model. The molecular response to anti-GPC1 mAb treatment in tumors was examined using Western 
blotting analysis. Results of the in vitro study revealed that CCD-19Lu lung fibroblasts, A549/CCD-19Lu and H460/CCD-19Lu co-culture spheroids were more sensitive to the cytotoxic effect of anti-GPC1 mAb as compared with A549 and H460 NSCLC cell monocultures. Results of the in vivo study showed that the anti-GPC1 mAb treatment was unable to inhibit A549 lung tumor growth significantly. Nonetheless, phosphorylation of FGFR1 at Tyr766 and Src at Tyr 416 was significantly decreased in anti-GPC1 mAb treated A549 lung tumors.

\section{Results}

\section{In Vitro Anti-GPC1 mAb Treatment Exhibited Greater Cytotoxic Potential Against CCD- 19Lu Lung Fibroblasts, A549/CCD-19Lu and H460/CCD-19Lu Coculture Spheroids than Against A549 and H460 Monocultures}

Evaluation of the in vitro cytotoxic effect of anti-GPC1 mAb in 2D A549, H460 and CCD19Lu monocultures was carried out using the 3-(4,5-dimethylthiazol-2-yl)-2-5diphenyltetrazolium bromide (MTT) assay after the cells were treated with anti-GPC1 mAb or mouse IgG isotype at concentrations ranging from 4.5 to $290 \mu \mathrm{g} / \mathrm{ml}$ for 72 hours. The effect of anti-GPC1 mAb on the viability of 3D A549 and H460 monoculture spheroids and A549/CCD19Lu and H460/CCD-19Lu coculture spheroids was determined using the CellTiter-Glo 3D reagent that generates the stable ATP-dependent luminescent signal. Results of the MTT assay showed that the IC50 values of anti-GPC1 mAb for A549 NSCLC cells and CCD-19Lu lung fibroblasts were significantly lower than that for $\mathrm{H} 460$ cells $(p<0.01$ for both. Fig. $1 A-1 C)$. Among the three cell lines tested, CCD-19Lu lung fibroblasts were shown with the lowest IC50 value, suggesting that the lung fibroblasts are more sensitive to anti-GPC1 mAb treatment than the NSCLC cells. Treatment with the mouse IgG isotype for 72 hours had no effect on the viability of all three cell lines tested (Fig. 1A $-1 \mathrm{C}$ ). Results of the 3D cell viability assay indicated that the IC50 values of anti-GPC1 mAb in A549/CCD-19Lu and H460/CCD-19Lu coculture spheroids were $15 \%$ and $44 \%$ lower, respectively, than those in A549 and H460 monoculture spheroids ( $p<0.01$ for both. Fig. 1D - 1E), suggesting tumor cell-fibroblast cocultures are more sensitive to the cytotoxic effect of anti-GPC1 mAb than tumor cell monocultures.

\section{Ani-GPC1 Effectively Inhibited Anchorage-Independent Growth of A549 and H460 Tumor Cells}

In soft agar colony formation assay, tumor cells were deprived of their anchorage by being suspended in $0.3 \%$ noble agar as single cells (Fig. $2 \mathrm{~A}$ ). The relative number of colonies (\% control) and percent of well area covered by colonies (\% colony area) were determined to quantify the inhibitory effect of anti-GPC1 mAb on tumor cell survival and proliferation under the anchorage-independent condition. For A549 cells, treatment with 40 and $60 \mu \mathrm{g} / \mathrm{ml}$ of anti-GPC1 $\mathrm{mAb}$ resulted in a significantly less number of colonies as compared with the number of colonies formed in the vehicle control and $80 \mu \mathrm{g} / \mathrm{ml}$ mouse IgG isotype groups ( $p<0.01$ for all. Fig. 2B). Treatment with 20,40 and $60 \mu \mathrm{g} / \mathrm{ml}$ of anti-GPC1 mAb also significantly inhibited the anchorage-independent growth of A549 cells, which was reflected by the significant decrease in the \% colony areas in the anti-GPC1 mAb treated A549 cells as compared with those in A549 cells treated with the vehicle control or $80 \mu \mathrm{g} / \mathrm{ml}$ mouse IgG isotype. For H460 cells, treatment with 10 and $20 \mu \mathrm{g} / \mathrm{ml}$ of anti-GPC1 mAb resulted in a significant decrease in the relative number of colonies formed as compared with the vehicle treatment $(p<0.01$ for all. Fig. $2 B)$. Treatment with 5,10 and $20 \mu \mathrm{g} / \mathrm{ml}$ of anti-GPC1 mAb significantly decreased the \% colony areas as compared with treatment with vehicle or $40 \mu \mathrm{g} / \mathrm{ml}$ of mouse IgG isotype. The inhibitory effect of anti-GPC1 mAb on the colony formation was concentration dependent irrespective of the cell line used ( $p<0.01$ for all. Pearson's correlation). It was noted that the estimated concentrations 
at which $50 \%$ of colony formation was inhibited were significantly lower than the IC50 values obtained from the MTT assay performed in 2D cell culture $(41.2 \pm 0.93 \mathrm{vs} 169 \pm 19.2 \mu \mathrm{g} / \mathrm{ml}$ for A549 cells; $13.6 \pm 0.59$ vs $646 \pm 103 \mu \mathrm{g} / \mathrm{ml}$ for $\mathrm{H} 460$ cells. $\mathrm{p}<0.01$ for both. Fig. $1 \mathrm{~A}, 1 \mathrm{~B}$ and 2B). This finding suggests that the anchorage-independent tumor cell growth is more sensitive to anti-GPC1 mAb treatment.

\section{Anti-GPC1 mAb Reduced the Invasion Capacity of Tumor Cell/Fibroblast Coculture Spheroids}

The 3D spheroid invasion assay was conducted to evaluate the effect of anti-GPC1 mAb on the invasion potential of A549 and H460 tumor cells that were either monocultured or cocultured with CCD-19Lu fibroblasts (Fig. 3). The final concentrations of anti-GPC1 mAb used in monoculture and coculture spheroids were 50 and $100 \mu \mathrm{g} / \mathrm{mL}$. As indicated by the fold change in cell-covered area relative to Day 0, treatment with anti-GPC1 mAb at 50 and $100 \mu \mathrm{g} / \mathrm{mL}$ had little effect on the invasion potential of A549 and H460 monoculture spheroids as compared with the vehicle control or $100 \mu \mathrm{g} / \mathrm{mL}$ mouse IgG isotype treatment (Fig. 3A and 3C). GPC1 is known to function as a co-receptor/modulator of various growth factors to enhance the binding to their

respective receptors ${ }^{3-10}$, and cancer-associated fibroblasts are an important contributor of some of those growth factors in tumors, including FGF2 and TGF- $\beta{ }^{29,30}$. In this regard, the tumor cell/fibroblast coculture spheroids were used to evaluate the anti-invasion potential of anti-GPC1 mAb. A549/CCD-19Lu coculture spheroids treated with $100 \mu \mathrm{g} / \mathrm{ml}$ of anti-GPC1 mAb exhibited significantly reduced cell-covered areas compared with those treated with vehicle control or 100 $\mu \mathrm{g} / \mathrm{ml}$ of mouse IgG isotype from Day 2 through 4 ( $p<0.05$ for all. Fig. 3B). In H460/CCD-19Lu coculture spheroids, treatment with anti-GPC1 $\mathrm{mAb}$ at 50 and $100 \mu \mathrm{g} / \mathrm{ml}$ resulted in significantly less cell-covered areas than treatment with $100 \mu \mathrm{g} / \mathrm{ml}$ of mouse lgG isotype on Day 2 ( $p<0.01$ for both), Day 3 ( $p<0.01$ for both) and Day 4 ( $p<0.05$ for both. Fig. 3D). Overall, these results suggest that anti-GPC1 mAb treatment inhibits fibroblast-led collective tumor cell invasion.

\section{Evaluation of Molecular Changes in Response to Anti-GPC1 mAb Treatment in Monocultured and Co-Cultured NSCLC Cells and Lung Fibroblasts}

Since GPC1 is believed to facilitate the activation of signaling pathways downstream of the receptors of heparin-binding growth factor family of proteins, it is anticipated that anti-GPC1 mAb blocks the interaction between GPC1 and those growth factors, and subsequently hinders the activation of the cognate receptors and downstream pathways. In this study, A549, H460 and CCD-19Lu cells that were cultured as monocultures or co-cultured in an indirect transwell co-culture system were exposed to vehicle control, $100 \mu \mathrm{g} / \mathrm{ml}$ of mouse lgG isotype or 100 $\mu \mathrm{g} / \mathrm{ml}$ of anti-GPC1 mAb for 24 hours. The collected whole cell lysate samples were subjected to Western blotting analysis to examine the effect of in vitro anti-GPC1 mAb treatment on common downstream growth factor receptor signaling pathways, including the MEK/ERK/RSK, Akt/GSK3/mTOR and Src/FAK pathways, as well as the protein expression of GPC1 and selected EMT markers, including $\beta$-catenin and vimentin. As shown in Supplementary Fig. S1, GPC1 protein expression was detected in all three cell lines by Western blotting, indicating that the target antigen of anti-GPC1 mAb is present in all three cell lines tested. In monocultures, treatment with anti-GPC1 mAb had no effect on the levels of phosphorylated signaling effectors and the protein expression of GPC1, $\beta$-catenin and vimentin proteins in A549 and H460 NSCLC cell lines (Supplementary Fig. S1). However, in CCD-19Lu lung fibroblast monocultures, as compared with both of the vehicle control and mouse IgG isotype control treatment, anti-GPC1 mAb treatment significantly decreased the FAK phosphorylation at Tyr 397 ( $p<0.01$ for both), RSK phosphorylation at Ser380 ( $p<0.05$ for both), Akt phosphorylation at Ser473 ( $p<0.01$ for both), and vimentin protein expression ( $p<0.05$ compared with the vehicle control and $p<0.01$ compared with the mouse IgG isotype) (Fig. 4A). Moreover, compared with the vehicle control 
treatment, the anti-GPC1 mAb treatment significantly decreased the expression of phosphomTOR at Ser2448 in CCD-19Lu fibroblasts $(p<0.05)($ Fig. 4A). These data indicated that the anti-GPC1 mAb treatment significantly decreased the activities of FAK, Akt, mTOR and RSK in CCD-19Lu lung fibroblasts, suggesting that the antiproliferative effect of anti-GPC1 mAb on CCD-19Lu lung fibroblasts is attributable to its inhibitory effect on the FAK/Src, Akt/mTOR, MEK/ERK/RSK pathways (Fig. 1C and Fig. 4A). The significant decrease in vimentin protein expression in anti-GPC1 treated CCD-19Lu cells may be associated with the suppression of fibroblasts proliferation and activity in vitro (Fig. 4A). When CCD-19Lu lung fibroblasts were cocultured indirectly with $\mathrm{H} 460$ lung tumor cells, anti-GPC1 mAb treatment significantly decreased the phosphorylation of Src at Tyr416 and $\beta$-catenin protein expression as compared with both of the vehicle control and mouse IgG isotype control treatment $(p<0.01$ for all) (Fig. 4B;

Supplementary Fig. S2). Moreover, the expression of phospho-Akt at Ser473 in anti-GPC1 mAb treated CCD-19Lu fibroblasts was significantly lower than that in the vehicle control-treated CCD-19Lu fibroblasts ( $p<0.05)$, while the expression of phospho-MEK at Ser217/221 in antiGPC1 mAb treated CCD-19Lu fibroblasts was significantly lower than that in the mouse IgG isotype-treated CCD-19Lu fibroblasts $(p<0.05)$ (Fig. 4B). When CCD-19Lu lung fibroblasts were co-cultured indirectly with A549 cells, the anti-GPC1 mAb treatment significantly decreased the expression of phospho-Src (Tyr416) ( $p<0.01$ for both), phospho-Akt (Ser473) ( $p$ $<0.05$ for both) and $\beta$-catenin protein ( $p<0.01$ for both) as compared with both of the vehicle control and mouse IgG isotype treatment (Fig. 4C; Supplementary Fig. S2). In addition, in the co-cultured A549 cells, the anti-GPC1 mAb treatment significantly decreased the RSK phosphorylation at Ser380 ( $p<0.05$ compared with both of the vehicle and mouse IgG isotype controls) and MEK phosphorylation at Ser217/221 ( $p<0.05$ compared with the vehicle control)

(Fig. 4D). Taken together, results of the Western blot analysis of the in vitro monoculture and co-culture samples suggest that lung fibroblasts are more sensitive to anti-GPC1 mAb than lung tumor cells and the interaction between NSCLC cells and lung fibroblasts influences the molecular response to anti-GPC1 mAb treatment.

\section{In Vivo Response of Orthotopic A549 Xenograft Models to Anti-GPC1 mAb Treatment}

In light of the potential impact of anti-GPC1 mAb on the interaction between tumor cells and tumor associated fibroblasts observed in the in vitro model, we proceeded to explore the antitumor activity of anti-GPC1 mAb and associated mechanisms using an orthotopic A549 tumor xenograft model. In the initial study, the athymic nude mice bearing established orthotopic A549 lung tumors were given tail-vein injections of vehicle (saline) control, or $10 \mathrm{mg} / \mathrm{kg}$ mouse lgG isotype, or $10 \mathrm{mg} / \mathrm{kg}$ of anti-GPC1 mAb once every 72 hours for a total of 8 doses. The treatment was started once the progression of orthotopic lung tumor growth was confirmed by the in vivo bioluminescence imaging (BLI), which was 4 6 weeks after the intrapulmonary inoculation of luciferase expressing A549 tumor cells. BLI was conducted once a week over the 24 days of treatment period (Fig. 5A). The relative rate of lung tumor growth in the anti-GPC1 $\mathrm{mAb}$ group, which was calculated as the slope of the curve on the semi-logarithmic plot of BLI total signal intensity over time, was lower than those in the vehicle control and mouse IgG isotype groups, but the difference was not statistically significant $(p>0.05)$ (Fig. 5B). Likewise, the difference in total lung weights that reflect the lung tumor burden was not statistically significant among the three study groups ( $p>0.05$ ) (Fig. $5 \mathrm{C}$ ). In the second study, athymic nude mice was given the intraperitoneal (IP) injections of anti-GPC1 mAb at 1,10 and $50 \mathrm{mg} / \mathrm{kg}$ once a week for 3 doses and then once every 10 days for 2 more doses. The treatment was initiated 2 weeks after the orthotopic inoculation of A549 cells for early blockage of GPC1 activity. The in vivo BLI performed a week after the last dose showed that bioluminescence signals were detected in 6 out of 7 (6/7), 6/8, 4/8, and 6/7 animals in the vehicle control, $1 \mathrm{mg} / \mathrm{kg}, 10 \mathrm{mg} / \mathrm{kg}$ and $50 \mathrm{mg} / \mathrm{kg}$ anti-GPC1mAb groups, respectively (Fig. 6A). Tumor nodules were found in the lungs of two more animals in the $10 \mathrm{mg} / \mathrm{kg}$ anti-GPC1 mAb group during the macroscopic 
inspection. Animals failed to develop macroscopic tumors in the lungs were excluded from further analyses. Results of the ELISA determination of the anti-GPC1 mAb levels in plasma on the final day of the experiment showed that the anti-GPC1 mAb plasma levels were strongly correlated with the administered dose (Pearson's correlation coefficient $=0.9986, p<0.01$ ) (Fig. 6B). Tumor-bearing mice treated with $50 \mathrm{mg} / \mathrm{kg}$ anti-GPC1 mAb had 43-, 17- and 2-fold increase in the mean anti-GPC1 mAb plasma levels as compared with the control, $1 \mathrm{mg} / \mathrm{kg}$ and $10 \mathrm{mg} / \mathrm{kg}$ anti-GPC1 mAb groups, respectively ( $p<0.01$ for all) (Fig. 6B). The mean anti-GPC1 $\mathrm{mAb}$ level in the $10 \mathrm{mg} / \mathrm{kg}$ group was significantly higher than that in the control group (11-fold increase, $p<0.05$ ) (Fig. 6B). These data indicated that IP administration of 5 doses of antiGPC1 $\mathrm{mAb}$ at 10 and $50 \mathrm{mg} / \mathrm{kg}$ over 41 days elicited significantly higher mAb plasma levels as compared with the vehicle control. With regard to the effect of anti-GPC1 mAb treatment on tumor burden, although the mean total lung weights in the 10 and $50 \mathrm{mg} / \mathrm{kg}$ anti-GPC1 mAb groups were decreased by $28 \%$ and $14 \%$ as compared with those of the control group, the differences were not statistically significant ( $p>0.05$. Fig. $6 \mathrm{C})$.

\section{Evaluation of Molecular Changes in Response to Anti-GPC1 mAb Treatment in Othotopic A549 NSCLC Xenografts and Adjacent Normal Lung Tissues}

The effect of in vivo anti-GPC1 mAb treatment on signaling pathways associated with aberrant activation of growth factor receptors, including the MEK/ERK/RSK, Akt/GSK3/mTOR and Src/FAK pathways, as well as the protein expression of selected EMT markers, was evaluated in A549 lung tumors and adjacent noncancerous lung tissues using Western blot analysis (Supplementary Fig. S3 - S6). The intravenous administration of $10 \mathrm{mg} / \mathrm{kg}$ anti-GPC1 mAb once every 72 hours for a total of 8 doses did not have any significant effect on the phosphorylation of MEK, ERK, RSK, Akt, GSK3a/ $\beta$, mTOR, Src and FAK, nor did it change significantly the expression of E-cadherin and $\beta$-catenin protein in orthotopic A549 lung tumors and adjacent normal lung tissues (Fig. 7A and 7B; Supplementary Fig. S3).

In contrast, the intraperitoneal administration of anti-GPC1 mAb at 10 and $50 \mathrm{mg} / \mathrm{kg}$ once a week for 3 doses and then once every 10 days for 2 more doses appeared to attenuate the FGF signal transduction pathway in the orthotopic A549 NSCLC xenografts (Supplementary Fig. S4 and S5). Treatment with 10 and $50 \mathrm{mg} / \mathrm{kg}$ anti-GPC1 mAb significantly inhibited the FGFR1 phosphorylation at Tyr766 ( $p<0.05$ for both treatment groups) (Fig. 8A. Supplementary Fig. S5), as well as the downstream ERK phosphorylation at Thr202/Tyr204 and RSK phosphorylation at Ser380 in tumors, as compared with the control group ( $p<0.01$ for all) (Fig. 8B. Supplementary Fig. S4). The relative expression levels of phospho-GSK3a (Ser21) $(p<$ 0.05 for $1 \mathrm{mg} / \mathrm{kg}$, and $\mathrm{p}<0.01$ for 10 and $50 \mathrm{mg} / \mathrm{kg}$ groups), phospho-GSK3 $\beta$ (Ser9) $(p<0.01$ for all) and phospho-Src (Tyr416) ( $p<0.05$ for $1 \mathrm{mg} / \mathrm{kg}$, and $p<0.01$ for 10 and $50 \mathrm{mg} / \mathrm{kg}$ groups) were significantly decreased in all anti-GPC1 mAb treated tumors as compared with those in the control group (Fig. 8B. Supplementary Fig. S4). Moreover, comparison among the treatment groups showed that the expression levels of phospho-Src (Tyr416) in A549 tumors treated with 10 and $50 \mathrm{mg} / \mathrm{kg}$ anti-GPC1 mAb were significantly lowered than those treated with $1 \mathrm{mg} / \mathrm{kg}$ anti-GPC1 mAb ( $<0.05$ for both 10 and $50 \mathrm{mg} / \mathrm{kg}$ groups). The phospho-ERK (Thr202/Tyr204) expression in the $10 \mathrm{mg} / \mathrm{kg}$ group was significantly lower than that in the 1 $\mathrm{mg} / \mathrm{kg}$ group ( $\mathrm{p}<0.05$ ), while the phospho-MEK (Ser380) expression in the $10 \mathrm{mg} / \mathrm{kg}$ group was significantly lower than those in the $1 \mathrm{mg} / \mathrm{kg}(\mathrm{p}<0.01)$ and $50 \mathrm{mg} / \mathrm{kg}(\mathrm{p}<0.05)$ groups (Fig. $8 \mathrm{~B})$. It was noted that treatment with anti-GPC1 mAb at 10 and $50 \mathrm{mg} / \mathrm{kg}$ resulted in a significant decrease in the intratumoral E-cadherin protein expression as compared with the vehicle treatment (Fig. $8 \mathrm{C}$ ), raising the concern that anti-GPC1 mAb treatment might elicit EMT in tumors.

In adjacent noncancerous lung tissues, anti-GPC1 mAb had no effect on the phosphoFGFR1 (Tyr766) expression ( $p>0.05$ ) (Fig. 8D. Supplementary Fig. S6). Anti-GPC1 mAb 
treatment at 10 and $50 \mathrm{mg} / \mathrm{kg}$ significantly decreased the phospho-Src (Tyr416) expression as compared with the vehicle control $(p<0.05$ and $p<0.01$ for 10 and $50 \mathrm{mg} / \mathrm{kg}$ anti-GPC1 mAb treatment, respectively) and the $1 \mathrm{mg} / \mathrm{kg}$ anti-GPC1 mAb treatment group ( $p<0.05$ and $p<$ 0.01 for 10 and $50 \mathrm{mg} / \mathrm{kg}$ anti-GPC1 mAb groups, respectively) (Fig. 8E. Supplementary Fig. S4). Moreover, the phospho-p90RSK (Ser380) expression levels in the 10 and $50 \mathrm{mg} / \mathrm{kg}$ antiGPC1 mAb treatment groups were significantly lower than that in the $1 \mathrm{mg} / \mathrm{kg}$ group $(\mathrm{p}<0.01$ for both) (Figure 8E). A significant difference in the phospho-p90RSK (Ser380) expression level in the noncancerous lung tissues was found between control and $10 \mathrm{mg} / \mathrm{kg}$ anti-GPC1 mAb groups $(p<0.05)$, while a significant difference in the phospho-FAK (Tyr397) expression levels was found between control and $10 \mathrm{mg} / \mathrm{kg}$ anti-GPC1 mAb treatment groups $(\mathrm{p}<0.05)$ (Fig. 8E). It was noted that the protein expression of GPC1 was detectable using the anti-GPC1 mAb, which is developed to target human GPC1, suggesting that the anti-GPC1 mAb is cross-reactive with the mouse GPC1. Treatment with the anti-GPC1 mAb at all three dose levels significantly decreased the vimentin protein expression levels in the adjacent noncancerous lung tissues ( $p$ $<0.05$ for all) (Fig. 8F), implicating that certain types of cells in normal lung tissue, such as lung fibroblasts, may be sensitive to anti-GPC1 mAb treatment.

\section{Discussion}

The distinct role of GPC1 in promoting the progression of certain types of solid tumors has rendered it an attractive target for cancer therapy. Since inhibition of GPC1 activity with an antiGPC1 mAb has shown promising anti-tumor effect in a GPC1-positive ESCC xenograft model, it is anticipated that GPC1 targeted therapies can be developed for other GPC1-positive solid tumors ${ }^{28}$. So far the therapeutic potential of selective inhibition of GPC1 for NSCLC treatment has not been documented, partly because of the unclear clinicopathological significance and diagnostic role of GPC1 in NSCLC ${ }^{21,22}$. In order to verify the expression level of GPC1 mRNA in NSCLC, we analyzed 10 public microarray datasets in Gene Expression Omnibus (Series: GSE3268; Accession number: GDS1312; Gene probe: 202756_s_at). The calculated log2 transformed fold change of GPC1 mRNA levels indicated that GPC 1 was up-regulated with 2.38-fold change in the squamous cell lung carcinoma biopsy specimens as compared with that in the paired normal lung tissues (adjusted $p$ value $=0.00399$ ) (Supplementary Fig. S7). Given the clinical relevance of GPC1 expression in NSCLC, this study was focused on evaluating the effect of a new anti-GPC1 mAb on lung tumor growth using in vitro and in vivo models and exploring the associated mechanisms.

In the in vitro cytotoxicity study, the anti-GPC1 mAb cytotoxicity was found in an ascending order with monocultured H460 cells (mean IC50 $=646 \mu \mathrm{g} / \mathrm{mL}$ ) $<$ A549 cells (mean IC50 = 169 $\mu \mathrm{g} / \mathrm{mL}$ ) $<$ CCD-19Lu fibroblasts (mean IC50 = 60 $\mu \mathrm{g} / \mathrm{mL}$ ), indicating that lung fibroblasts are more sensitive to the cytotoxic effect of anti-GPC1 mAb than NSCLC cells (Fig. 1). Consistent with the finding obtained from monocultured cells, A549/CCD-19Lu and H460/CCD-19Lu coculture spheroids appeared to be more sensitive to the cytotoxic effect of anti-GPC1 mAb than A549 and H460 monoculture spheroids. Moreover, anti-GPC1 mAb was found to exhibit profound inhibitory effect on the anchorage-independent growth of A549 and H460 cells (Figure 2). Given that the anchorage-independency bestows upon tumor cells the potential to colonize distant organs and form malignant lesions ${ }^{31}$, anti-GPC1 mAb treatment is likely to be effective against tumorigenesis and cancer metastasis. Furthermore, anti-GPC1 mAb treatment significantly inhibited the invasion potential of tumor cell/fibroblast coculture spheroids but not the tumor cell monoculture spheroids (Fig. 3), suggesting that anti-GPC1 mAb suppresses fibroblast-led collective invasion of tumor cells by inhibiting the fibroblast activity ${ }^{32}$.

Consistent with the results of in vitro cytotoxicity and invasion assays, the anti-GPC1 mAb treatment had little effect on the levels of phosphorylated signaling effectors that are major regulators of cell proliferation and survival in monocultured A549 and H460 cells (Fig. 3 and 
Supplementary Fig. S1). In contrast, the anti-GPC1 mAb treatment significantly inhibited the phosphorylation of FAK at Tyr397, RSK at Ser380, Akt at Ser473 and mTOR at Ser2448 in monocultured CCD-19Lu lung fibroblasts, suggesting that the inhibitory effect of anti-GPC1 mAb on lung fibroblast proliferation is attributable to the deactivated Akt/mTOR pathway and reduced FAK and RSK activities (Fig. 4A). However, when CCD-19Lu lung fibroblasts were co-cultured indirectly with A549 or $\mathrm{H} 460$ tumor cells, anti-GPC1 mAb significantly decreased the phosphorylation of Src at Tyr416 and Akt at Ser473 and the $\beta$-catenin protein expression level in CCD-19Lu fibroblasts (Fig. 4B and 4C), and the expression of phospho-MEK (Ser217/221) and phospho-RSK (Ser380) in co-cultured A549 cells (Fig. 4D). The difference in molecular response to anti-GPC1 mAb treatment between monocultured and co-cultured lung fibroblasts and tumor cells implicates that anti-GPC1 mAb impairs the reciprocal crosstalk between tumor cells and tumor associated fibroblasts.

Since the mean IC50 value of anti-GPC1 mAb in A549 cells determined after 72-hour treatment in vitro was $0.169 \mathrm{mg} / \mathrm{mL}$, and given the fact that an adult male mouse usually has a circulating blood volume of about $58.5 \mathrm{~mL} / \mathrm{kg}$ body weight (https://nc3rs.org.uk/mouse-decisiontree-blood-sampling), athymic nude mice with established orthotopic A549 lung tumors were given the intravenous (IV) administration of the anti-GPC1 $\mathrm{mAb}$ at a dose of $10 \mathrm{mg} / \mathrm{kg}$ once every 72 hours for eight doses in the initial in vivo study $(0.169 \mathrm{mg} / \mathrm{mL} \times 58.5 \mathrm{~mL} / \mathrm{kg}=9.9$ $\mathrm{mg} / \mathrm{kg} \approx 10 \mathrm{mg} / \mathrm{kg}$ ). Although the anti-GPC1 mAb treatment reduced the mean relative rate of lung tumor growth, the difference was not statistically different between the anti-GPC1 mAb treatment group and the control groups (including both vehicle and $10 \mathrm{mg} / \mathrm{kg}$ mouse $\mathrm{lgG}$ isotype groups) $(p>0.05)$ (Fig. 5B). Consistent with the relative lung tumor growth rate data, the mean total lung weight in the anti-GPC1 mAb group was not significantly different from those in the vehicle and mouse IgG isotype groups (Fig. 5C). Moreover, results of the Western blot analysis of tumor samples indicated that the short-term anti-GPC1 mAb treatment had little effect on the activity of the MEK/ERK/RSK and Akt/GSK3/mTOR pathways (Figure 7 and Supplementary Fig. S3). Although the anti-GPC1 mAb treatment appeared to reduce the FAK Tyr397 and Src Ser416 phosphorylation in tumors by $34 \%$ and $52 \%$, respectively, as compared with the vehicle control treatment, the difference was not statistically significant due to large interindividual variability (Fig. 7A). The lack of anti-tumor effect of the short-term anti-GPC1 mAb treatment against the established orthotopic A549 lung tumors and the profound inhibitory effect of antiGPC1 mAb on anchorage-independent A549 cell growth in vitro prompted us to test the effect of anti-GPC1 mAb on preventing tumor development in tumor-bearing mice using a modified antiGPC1 mAb dosing regimen.

In the second in vivo study, the anti-GPC1 mAb treatment was started two weeks after the orthotopic inoculation of A549 tumor cells for early blockage of GPC1 activity. The dosage regimen for anti-GPC1 mAb was modified to intraperitoneal administration of the mAb at dose levels of 1,10 and $50 \mathrm{mg} / \mathrm{kg}$ once a week for 3 doses and then once every 10 days for 2 more doses. With the modified dosage regimen, the anti-GPC1 mAb plasma levels determined in the 10 and $50 \mathrm{mg} / \mathrm{kg}$ groups seven days after the last dose were 11- and 43-fold, respectively, higher than that in the vehicle control group ( $p<0.05$ and $<0.01$, respectively) (Fig. 6B), implicating the slow clearance and long half-life of the anti-GPC1 mAb ${ }^{33}$. Although the modified anti-GPC1 mAb dosage regimen was unable to reduce the lung tumor burden significantly as reflected by the total lung weight (Figure 6C), the anti-GPC1 mAb treatment significantly inhibited the FGFR1 phosphorylation at Tyr766 in tumors without affecting the FGF-2 levels in tumors and subsequently reduced the phosphorylation of several prominent effectors downstream of the FGFR1, including ERK ${ }^{34}$, RSK, GSK3 $\alpha$ and GSK3 $\beta$ (Fig. 8. Supplementary Fig. S4 - S6). The possible mechanism underlying the inhibitory effect of the anti-GPC1 mAb on the FGFR1 signaling is two-fold. On the one hand, since GPC1 is known to act as a co-receptor 
by sequestering the FGFs on the cell surface, stabilizing the FGF ligand-receptor interaction and subsequently improving the efficiency of FGF-activated FGFR1 signaling pathways in tumor cells $^{4,5,35}$, it is conceivable that inhibition of GPC1 activity with the anti-GPC1 mAb is able to impede the activation of signaling pathways downstream of FGFR1. In this study, it appeared that the MEK/ERK/RSK signaling pathway was affected by the GPC1 inhibition more significantly than the Akt/mTOR signaling pathway in A549 orthotopic lung tumors, and inhibition of the MEK/ERK/RSK signaling was associated with the decreased phosphorylation of GSK3 $\alpha$ and GSK3 ${ }^{36,37}$ (Fig. 9). This proposed mechanism was in line with the in vitro finding that antiGPC1 mAb treatment significantly decreased the expression of phospho-MEK and phosphop90RSK in A549 cells that were cultured in indirect co-culture with the CCD-19Lu lung fibroblasts $(p<0.05$ for both as compared with the vehicle control) (Figure 4D). On the other hand, since tumor associated fibroblasts can secrete high amounts of growth factors, such as TGF- $\beta$, HGF and FGF, to stimulate tumor progression ${ }^{38}$, it is postulated that anti-GPC1 mAb treatment reduces the production of those growth factors by inhibiting the proliferation and activities of tumor associated fibroblasts. This hypothesis was supported by our in vitro data indicating that the lung fibroblasts were more sensitive to the cytotoxic effect of anti-GPC1 mAb as compared with the A549 and H460 lung tumor cells (Fig. 1 and Fig. 4).

Results of the initial in vivo study showed that short-term anti-GPC1 mAb treatment resulted in 52\% decrease in the phosphorylation of Src at Tyr416 in tumors as compared with the vehicle control (Fig. 7A). However, the difference was not statistically significant. Results of the second in vivo study, in which intraperitoneal administration of anti-GPC1 mAb at a modified dosing regimen was started two weeks after tumor cell inoculation, demonstrated that anti-GPC1 mAb treatment at 1,10 and $50 \mathrm{mg} / \mathrm{kg}$ significantly reduced the phospho-Src (Tyr416) levels in A549 tumors by $35 \%(p<0.05), 75 \%(p<0.01)$ and 68\% $(p<0.01)$, respectively (Fig. 8B). Src is a cytoplasmic nonreceptor tyrosine kinase involved in multiply signaling pathways ${ }^{39}$. It is evident that Src can be constitutively associated with or recruited onto the cholesterol/sphingolipidsenriched microdomains in plasma membrane, also known as "lipid rafts", to coordinate receptor signal transduction ${ }^{40,41}$. It has been reported that the active Src is recruited to the FGF-2activated FGFR1 located at the plasma membrane to influence FGFR1 signaling dynamics through the adaptor protein factor receptor substrate 2 (FRS2) ${ }^{42,43}$. FRS2 is a lipid raftassociated protein serving as the primary link between FGFR and a variety of downstream pathways ${ }^{44}$. Without FGF-2 stimulation, Src stays inactive in a cytoplasmic and tight perinuclear position showing undetectable Tyr416 phosphorylation ${ }^{43}$. In this regard, anti-GPC1 mAb may attenuate the binding affinity of FGF-2 for FGFR1 and impede the activation of FGFR1 and subsequent recruitment of active Src onto the plasma membrane (Figure 9). Other GPC1facilitated growth factor encounters with receptor signaling may also require the Y416 phosphorylation of Src and recruitment of active Src onto the cell membrane. For example, Cripto-1 (CR-1), a member of the epidermal growth factor/Cripto/ FRL-1/Cryptic (EGF-CFC) gene family with the glycosylphosphatidylinositol (GPI) anchorage domain (Ser161-Try188) attached to lipid rafts ${ }^{45,46}$, has been shown to specifically bind to GPC1 and subsequently activate the cytoplasmic Src ${ }^{47}$. Given that CR-1 is often expressed at high levels in NSCLC ${ }^{48,49}$, it is possible that the anti-GPC1 mAb treatment hinders the interaction between $\mathrm{CR}-1$ and its cognate receptors, thereby alleviating the need for recruiting the phosphorylated Src in cytoplasm.

In the in vitro study, results of the Western blotting revealed that the anti-GPC1 mAb treatment significantly decreased the vimentin protein expression levels in cultured CCD-19Lu fibroblasts that do not express E-cadherin protein at detectable levels (data not shown), while the vimentin and E-cadherin protein expression levels in A549 and $\mathrm{H} 460$ cells were not affected by the treatment (Fig. 4), suggesting that the inhibitory effect of anti-GPC1 mAb on tumor cell invasion is not associated with changes in the EMT process of tumor cells but the attenuated 
activities of tumor associated fibroblasts. In the in vivo study, the vimentin protein expression in normal lung tissues was significantly decreased in all anti-GPC1 mAb treatment groups, while the E-cadherin protein expression in A549 lung tumors was significantly decreased in 10 and 50 $\mathrm{mg} / \mathrm{kg}$ anti-GPC1 mAb treatment groups (Fig. 8). Since vimentin is required for early-stage lung adenocarcinoma dissemination by acting as a regulator of the motility of tumor associated fibroblasts ${ }^{50}$, the observed decrease in vimentin protein expression in anti-GPC1 mAb-treated monocultured CCD-19Lu lung fibroblasts and in mouse lung tissues implicates that the antiGPC1 mAb may inhibit the fibroblasts-led collective invasion of tumor cells ${ }^{51}$. Although it has been reported that inhibition of Src activity led to the inhibition of E-cadherin removal from cell membrane and lysosomal degradation ${ }^{52,53}$, the exact mechanism involved in the decreased $\mathrm{E}$ cadherin protein level in anti-GPC1 mAb treated A549 tumors remains unclear.

Taken together, our data implicate that the antitumor potential of anti-GPC1 mAb lies in its ability to impede the GPC1-facilitated encounter of FGF2 with FGFR that requires the Y416 phosphorylation of Src to initiate the signal transduction, and subsequently attenuate the downstream MEK/ERK/RSK signaling pathway (Fig. 9). This finding offers new insight into the molecular response to anti-GPC1 mAb treatment in NSCLC, providing rational basis for a combination strategy that incorporates a GPC1 inhibitor to sensitize tumors to certain targeted therapeutics. In addition, given the evidence of the cultured lung fibroblasts being more sensitive to anti-GPC1 mAb treatment than NSCLC cells, and the significantly decreased vimentin protein expression in anti-GPC1 mAb-treated monocultured CCD-19Lu lung fibroblasts and mouse lung tissues, it is postulated that selective inhibition of GPC1 may reduce the fibroblasts-led collective invasion of tumor cells. Further study is needed to investigate the impact of selective inhibition of GPC1 with anti-GPC1 mAb on the crosstalk between tumor cells and tumor associated firoblasts in NSCLC.

\section{Methods}

\section{Cell Lines and Cell Culture}

Two human non-small cell lung carcinoma cell lines, A549 and H460, and a human lung fibroblast cell line, CCD-19Lu, were purchased from the American Type Culture Collection (ATCC). The A549-Red-FLuc Bioware ${ }^{\circledR}$ Brite cell line, which has been stably transduced with the red-shifted firefly luciferase gene from Luciola Italica (Red-FLuc) will be purchased from PerkinElmer Inc (Waltham, WA). A549, A549-Red-Fluc, and CCD-19Lu cell lines were cultured in a mixture of Dulbecco's Modified Eagle's Medium (DMEM)/Ham's F12 at a ratio of 1:1 (Corning Inc., Corning, NY) supplemented with 10\% heat-inactivated fetal bovine serum (FBS) (Thermo Fisher Scientific, Waltham, MA ). The H460 cell line was cultured in RPMI-1640 medium (Corning Inc., Corning, NY) supplemented with $10 \%$ heat-inactivated FBS. Antibiotics were added to the cell culture media (100 units $/ \mathrm{ml}$ penicillin and $100 \mu \mathrm{g} / \mathrm{ml}$ streptomycin) to prevent contamination. All cells were maintained at $37^{\circ} \mathrm{C}$ in an atmosphere of humidified air with $5 \% \mathrm{CO}_{2}$. Cells were tested for mycoplasma using the MycoAlert kit periodically throughout the studies (Lonza. Allendale, NJ, USA).

\section{Animals}

Male athymic nude mice (Hsd: Athymic Nude-Foxn1nu; 5 6 weeks old) were purchased from Envigo (Indianapolis, IN). All animal experiments were approved by the Institutional Animal Care and Use Committee (IACUC) with the Project ID. of IS00005693 and conducted in the vivarium under the care of Department of Comparative Medicine at the University of South Florida. All procedures involving animals were performed in accordance with the relevant National Institute of Health (NIH) guidelines and regulations. All in vivo procedures were carried out in compliance with ARRIVE (Animal Research: Reporting of In Vivo Experiments) guidelines. 


\section{Preparation of Therapeutic Anti-Human GPC1 Mouse Monoclonal Antibody}

The therapeutic anti-human GPC1 mouse mAb was prepared by MnBiotech Inc. (Tampa, FL). In brief, human GPC1 gene and fragments (two overlap fragments with one from AA1-280 and the other one from AA240-559) were cloned into PGEX-6p-1 expression vector and expressed in BL21 bacteria. Fusion proteins were cleaved from Glutathione Sepharose 4B beads with PreScission Protease (Sigma-Aldrich Inc., St. Louis, Mo). For immunization and hybridoma generation, mouse splenocytes were isolated and fused with Sp2/0 mouse myeloma cells. Positive clones selected with human recombinant protein were amplified in large quantity. Antibodies were lyophilized after being isolated with protein A beads.

\section{MTT Assay}

The in vitro cytotoxic activity of anti-GPC1 mAb was determined in cultured A549 and H460 human NSCLC cells and CCD-19Lu human lung fibroblasts by a 3-(4,5-dimethylthiazol-2-yl)2,5-diphenyltetrazolium bromide (MTT) assay as described previously with minor modifications 54. A549 and H460 human NSCLC cells and CCD-19Lu lung fibroblasts were seeded in 96-well plates at a density of $4 \times 10^{3}$ cells/well and allowed to attach overnight. On the next day, culture media containing anti-GPC1 mAb $(4.5-290 \mu \mathrm{g} / \mathrm{ml})$ were added to appropriate wells. After the cells were treated for 72 hours, an aliquot of $10 \mu \mathrm{L}$ of $5 \mathrm{mg} / \mathrm{mL}$ MTT dissolved in phosphate buffered saline (PBS) was added to each well, and cells were incubated at $37^{\circ} \mathrm{C}$ for another $4 \mathrm{~h}$. Finally, cells were lysed for $1 \mathrm{~h}$ with the addition of $100 \mu \mathrm{L}$ of $100 \%$ DMSO. Plates were read at $570 \mathrm{~nm}$ on a SpectraMax 190 microplate reader equipped with SoftMax Pro software (Molecular Devices, Sunnyvale, CA). The growth of treated cells was expressed as a percentage of vehicle control cultures. The concentration of anti-GPC1 mAb required for $50 \%$ inhibition of cell growth (i.e., $\mathrm{IC}_{50}$ ) as compared with the control cells was calculated by nonlinear fitting of the experimental data obtained from multiple independent experiments performed in quadruplicates using the GraphPad Prism 5.0 program (GraphPad Software, Inc. La Jolla, CA).

\section{3-Dimentional Cytotoxicity Assay}

A549 and H460 monoculture spheroids and A549/CCD-19Lu and H460/CCD-19Lu coculture spheroids (in a tumor cell to fibroblast ratio of 1:1) were generated by seeding a total of 4,000 cells per well in $200 \mu \mathrm{l}$ of complete culture medium on a Spheron Nunclon 96-well plate (Thermo Fisher Scientific) followed by centrifugation at $400 \times \mathrm{g}$ for $10 \mathrm{~min}$. After the spheroids were cultured for $24 \mathrm{hrs}$, various amounts of anti-GPC1 mAb were added to achieve the final concentrations of 40,80,120,160 and $200 \mu \mathrm{g} / \mathrm{ml}$ and incubated for $72 \mathrm{hrs}$. After the 72 -hour treatment with the vehicle control and anti-GPC1 mAb, spheroid viability was measured by reading luminescence (Synergy Neo2 Hybrid Multi-Mode Reader. Biotek Instruments, Inc. Winooski, VT ) after 20 min incubation with CellTiter-Glo 3D reagent (50 $\mu \mathrm{L} /$ well) (Promega Co. Madison, WI) according to the manufacturer's protocol.

\section{Soft Agar Colony Formation Assay}

The inhibitory effect of anti-GPC1 mAb on the anchorage-independent growth of A549 and $\mathrm{H} 460$ tumor cells was evaluated using a modified two-layer soft agar culture system ${ }^{55}$. For the bottom layer of agar, $0.3 \mathrm{~mL}$ of complete culture medium containing $0.5 \%$ noble agar (Thermo Fisher Scientific. Waltham, MA) was added to each well of a 24-well plate. After the bottom layer was solidified, $2 \times 10 \mathrm{E} 3 \mathrm{~A} 549$ or $\mathrm{H} 460$ cells were suspended in $0.2 \mathrm{~mL}$ of the same culture medium containing $0.3 \%$ noble agar and vehicle control, or $100 \mu \mathrm{g} / \mathrm{mL}$ mouse lgG isotype, or anti-GPC1 mAb at various concentrations and placed on the base layer. After the upper layer of agar was solidified, $200 \mu \mathrm{l}$ of complete culture medium containing the same control or mAb at the same concentration as the upper layer of agar was added to prevent desiccation. Colony formation by A549 and H460 cells was evaluated after 10 12 days of culture for number and 
size of colonies. Twenty-four hours prior to the evaluation, $200 \mu \mathrm{l}$ of $1 \mathrm{mg} / \mathrm{ml}$ of MTT was added to each well for the evaluation of metabolic viability of the colonies ${ }^{56}$. Colonies were photographed using the Bio-Rad Gel Doc XR+ Gel Documentation system (Bio-Rad Laboratories, Inc. Hercules, CA). The number and size of colonies were quantified using ImageJ (https://imagej.nih.gov/ij/). Effect of the antibody treatment was expressed by relative number of colonies ${ }^{57}$ and percent of colony area ${ }^{58}$.

$$
\begin{aligned}
& \text { Relative number of colonies }(\%)=\frac{100 \times(\text { Colony count })_{\text {treatment }}}{(\text { Mean colony count })_{\text {vehicle control }}} \\
& \% \text { colony area }=\frac{100 \times(\text { Number of pixels in the region with an intensity above } 0)}{(\text { Total number of pixels in the same region })}
\end{aligned}
$$

\section{3-Dimentional Spheroid Invasion Assay}

To generate 3D tumor cell monoculture and tumor cell/fibroblast coculture spheroids, A549 or H460 cells alone (3000 cells per well), or A549 or H460 cells mixed with CCD-19Lu fibroblasts at a ratio of 1:1 (a total of 3000 cells per well), were added to a Spheron Nunclon 96well plate (Thermo Fisher Scientific) followed by centrifugation at $400 \times \mathrm{g}$ for $10 \mathrm{~min}$. After 3 days of incubation under the standard culture condition, spheroids were suspended in $1.5 \mathrm{mg} / \mathrm{ml}$ Cultrex $^{\mathrm{TM}}$ rat collagen I (R\&D Systems. Minneapolis, MN) diluted with the complete DMEM culture medium, and then transferred to a flat-botton 96 well pate. After collagen solidified, complete DMEM culture medium was added to the top of the collagen matrix to provide a chemogradient for the spheroids. To evaluate the effect of anti-GPC1 mAb on cell invasion, antiGPC1 $\mathrm{mAb}$ (50 and $100 \mu \mathrm{g} / \mathrm{mL}$ ) or mouse lgG isotype $(100 \mu \mathrm{g} / \mathrm{mL})$ was added directly to the collagen matrix to achieve the desired final concentration before solidification and to the complete culture medium on top of the solidified collagen matrix. Spheroids were maintained under the standard culture condition for 4 days to allow for invasion. Bright-field microscopy images were acquired daily on the EVOS ${ }^{\mathrm{TM}} \mathrm{XL}$ Imaging System (Thermo Fisher Scientific). Cellcovered area was measured using ImageJ (https://imagej.nih.gov/ij/).

\section{Transwell Indirect Co-Culture System}

The indirect tumor cell-fibroblast co-culture was carried out using a transwell system with Corning $^{\mathrm{TM}}$ Transwell $^{\mathrm{TM}} 24-\mathrm{mm}$ inserts and $0.4 \mu \mathrm{m}$ pore polyester membranes (Corning Inc., Corning, NY). A549 and H460 lung tumor cells were seeded in the lower chamber at the density of $5 \times 10 \mathrm{E} 4$ cells/well, while CCD-19Lu lung fibroblasts were in the upper chamber at the density of $10 \times 10 \mathrm{E} 4$ cells/insert. Co-cultured cells were maintained in DMEM/F12 media containing $10 \%$ FBS in the absence and presence of vehicle, mouse IgG isotype control or antiGPC1 mAb.

\section{Orthotopic A549-Red-Fluc Lung Tumor Model and In Vivo Bioluminescence Inmgaing}

The orthotopic lung tumor model was established by intrapulmonary injection of A549-RedFluc cells in athymic nude mice using the method described elsewhere with slight modifications 59. In brief, A549-Red-Fluc cells harvested during the exponential growth in vitro were suspended in PBS containing 10\% Matrige/ $\mathbb{B}$ Growth Factor Reduced (GFR) basement membrane matrix (Corning Inc., Corning, NY) prior to the tumor cell inoculation procedure. Athymic nude mice were anesthetized under isoflurane and positioned in the lateral decubitus position with the left chest facing up and a small $(\sim 5 \mathrm{~mm})$ incision was made in the skin just below the scapula. Next, the chest wall soft tissue was gently spread to expose the thoracic ribs and intercostal space to allow visualization of the left lobe of the lung. At this stage, $50 \mu \mathrm{l}$ of tumor cell suspension ( 1 x10E6 A549-Red-Fluc cells in $50 \mu \mathrm{L}$ PBS containing 10\% Matrige/ $\Theta$ GFR) was drawn into a 3/10-cc insulin syringe equipped with a 31-G hypodermic needle (Becton, Dickinson and Company, Franklin Lakes, NJ). Then the needle was inserted between the 6 th and 7th ribs and the tumor cell suspension was injected $5 \mathrm{~mm}$ deep into the left lung 
parenchyma over a 1-minute period. After injection of the cells, the syringe was withdrawn from the tissue and the initial surgery incision made in the skin was closed with non-absorbable Ethilon® 6-0 Nylon sutures. After the orthotopic inoculation of tumor cells, weekly in vivo bioluminescence imaging (BLI) was performed throughout the experiment using the IVIS ${ }^{\circ}$ Spectrum in vivo imaging system (Perkin Elmer Inc., Waltham, MA) to monitor changes in tumor burden over time in the same animals. To perform the in vivo $\mathrm{BLI}$, tumor bearing mice received intraperitoneal injection of $150 \mathrm{mg} / \mathrm{kg}$ D-luciferin (Gold Biotechnology) 8 minutes before imaging and were anesthetized with isoflurane during imaging. Bioluminescence emitted from each tumor bearing animal was acquired using the Living Image software (Perkin Elmer Inc., Waltham, MA). Region of interest (ROI) measurements on the images were used to convert surface radiance to total flux of photons expressed in photons/second and used as readout for the orthotopic lung tumor size. For longitudinal comparison of bioluminescence, ROI was manually selected and kept consistent across all experiments.

\section{In Vivo Treatment Protocol}

Intravenous Dosing Regimen: To evaluate the effect of anti-GPC1 mAb on orthotopic lung tumor growth, athymic nude mice were randomly divided into (1) vehicle control, (2) mouse IgG isotype $10 \mathrm{mg} / \mathrm{kg}$ and (3) anti-GPC1 mAb $10 \mathrm{mg} / \mathrm{kg}$ groups once the orthotopic lung tumor lesions were detected by BLI in those animals, which was at $4 \sim 6$ weeks after intrapulmonary tumor cell inoculation. Tumor-bearing animals were given intravenous (IV) injection of saline, 10 $\mathrm{mg} / \mathrm{kg}$ of mouse $\mathrm{lgG}$ isotype and $10 \mathrm{mg} / \mathrm{kg}$ of anti-GPC1 mAb through tail vein once every 72 hours for a total of 8 doses. All animals were euthanized 24 hours after the last dose. Plasma, lung tissue and tumor tissue samples collected from individual animals were stored at $-80^{\circ} \mathrm{C}$ before subjected to further analyses.

Intraperitoneal Dosing Regimen: To evaluate the efficacy of anti-GPC1 mAb treatment on orthotopic lung tumor growth, athymic nude mice were randomly divided into four groups: (1) vehicle control, (2) anti-GPC1 mAb $1 \mathrm{mg} / \mathrm{kg}$, (3) anti-GPC1 mAb $10 \mathrm{mg} / \mathrm{kg}$ and anti-GPC1 mAb $50 \mathrm{mg} / \mathrm{kg}$ groups. Two weeks after the orthotopic tumor cell inoculation, individual animals received intraperitoneal (IP) injection of saline or anti-GPC1 mAb at different dose levels once a week for 3 doses (i.e., on Day 0, 7 and 14) and then once every 10 days for 2 more doses (i.e., on Day 24 and 34). Animals were euthanized 1 week after the last dose (i.e., on Day 41). Superficial and internal macroscopic tumors in the lungs were assessed at necropsy. Those that failed to develop lung tumors were excluded from further analyses. Plasma, lung tissue and tumor tissue samples collected from individual tumor-bearing animals were stored at $-80^{\circ} \mathrm{C}$ before subjected to further analyses.

\section{Determination of Anti-GPC1 mAb Levels in Plasma Using ELISA}

A 96-well Immulon® Microtiter ${ }^{\mathrm{TM}}$ plate (Thermo Fisher Scientific) was coated with $50 \mu \mathrm{l}$ of recombinant human GPC1 protein $\left(2.5 \mu \mathrm{g} / \mathrm{ml}\right.$ in PBS) for 1 hour at $37^{\circ} \mathrm{C}$. After the coated plate was washed twice with PBS containing $0.1 \%$ Tween 20 (PBST) and blocked with $100 \mu \mathrm{l} /$ well of $1.5 \%$ BSA in PBST at $37^{\circ} \mathrm{C}$ for 30 minutes, an aliquot of $100 \mu \mathrm{l}$ of diluted plasma sample $(1: 200$ dilution in PBST containing $1.5 \%$ BSA) was added to each well and incubated at $37^{\circ} \mathrm{C}$ for 1 hour. After the plasma samples were removed, the plate was washed four times with PBST and then incubated with $100 \mu \mathrm{l} /$ well of diluted goat anti-mouse-HPR antibody (1:4000 dilution in PBST containing 1.5\% BSA) (Southern Biotech, Birmingham, AL) at $37^{\circ} \mathrm{C}$ for 1 hour. For colorimetric ELISA detection, $100 \mu \mathrm{l}$ of TMB (3,3',5,5'-tetramethylbenzidine) (Surmodics IVD, Inc., Eden Prairie, MN) was added to each well. After the plate was incubated at room temperature for $10 \sim 15$ minutes, the enzymatic reaction was stopped by adding $100 \mathrm{ul}$ of $0.4 \mathrm{M}$ of $\mathrm{H}_{2} \mathrm{SO}_{4}$ to each well. The plate was read at $450 \mathrm{~nm}$ on a SpectraMax 190 microplate reader 
equipped with SoftMax Pro software (Molecular Devices, Sunnyvale, CA). The optical density was used to estimate plasma levels of anti-GPC1 mAb.

\section{Western Blot Analysis}

Monocultured and co-cultured A549, H460 and CCD-19Lu cells, and normal lung and A549 lung tumor tissue samples collected from the in vivo studies were subjected to semi-quantitative Western blot analysis to determine the phosphorylation of downstream effectors of FGFR signaling, including the MEK/ERK/RSK, Akt/GSK3/mTOR and Src/FAK pathways, as well as the protein expression of GPC1 and selected EMT markers. A complete list of primary antibodies used in the Western blot analysis is shown in Supplementary Table S1.

\section{Statistical Analysis}

Statistical analyses were performed using Number Cruncher Statistical Systems 2007 (Keysville, UT). Data are presented as the mean \pm standard deviation (SD) unless otherwise indicated. The two-sample $t$-test was used to determine if there was a statistically significant difference between the means of two independent groups. Comparison of means between more than two independent groups was made using the one-way ANOVA followed by Tukey-Kramer post hoc multiple comparison test. To compare the tumor growth rate among three study groups, tumor sizes were transformed with square root and linear regressions were applied to fit the tumor growth curves for individual mice. Kruskal-Wallis tests was conducted to test the significant differences among groups. Pearson's correlation coefficient was used to describe the strength of linear correlation between two variables. A two-sided $p$-value of less than 0.05 was considered statistically significant.

Acknowledgments: This project was partially funded by USF Taneja College of Pharmacy Internal Research Funding (Q.Z.). The authors thank MegaNanoBiotech Inc. (Tampa, FL) for providing the anti-GPC1 monoclonal antibody for this study.

Author Contributions: Conceptualization: C.C., Q.Z.; Project administration: C.C., Q.Z.; Supervision: C.C. and Q.Z.; Methodology: M.L., Y.W., X.L., H.Y., X.Z., L.Z., F.C., C.C., Q.Z.; Data curation: M.L., Y.W., Q.Z.; Formal analysis: M.L., Y.W.; Y.B., L.Z., F.C., C.C., Q.Z.; Writing - original draft: M.L., Y.W., Q.Z.; Writing - review \& editing: C.C., Q.Z.; Resources: Y.B., X.L., L.Z., C.C., Q.Z..

Competing Interests: The authors declare no competing interests.

Availability of data: Data generated during and/or analyzed during the current study are available from the corresponding author on reasonable request.

\section{References}

1 Siegel, R. L., Miller, K. D. \& Jemal, A. Cancer statistics, 2018. CA: a cancer journal for clinicians 68, 7-30, doi:10.3322/caac.21442 (2018).

2 Yuan, M., Huang, L. L., Chen, J. H., Wu, J. \& Xu, Q. The emerging treatment landscape of targeted therapy in non-small-cell lung cancer. Signal Transduct Target Ther 4, 61, doi:10.1038/s41392019-0099-9 (2019).

3 Paulick, M. G. \& Bertozzi, C. R. The glycosylphosphatidylinositol anchor: a complex membraneanchoring structure for proteins. Biochemistry 47, 6991-7000, doi:10.1021/bi8006324 (2008).

4 Gutierrez, J. \& Brandan, E. A novel mechanism of sequestering fibroblast growth factor 2 by glypican in lipid rafts, allowing skeletal muscle differentiation. Molecular and cellular biology 30, 1634-1649, doi:10.1128/MCB.01164-09 (2010). 

signaling in glioma cells. The American journal of pathology 168, 2014-2026, doi:10.2353/ajpath.2006.050800 (2006).

6 Kayed, H. et al. Correlation of glypican-1 expression with TGF-beta, BMP, and activin receptors in pancreatic ductal adenocarcinoma. International journal of oncology 29, 1139-1148 (2006).

7 Gutierrez, J., Cabrera, D. \& Brandan, E. Glypican-1 regulates myoblast response to HGF via Met in a lipid raft-dependent mechanism: effect on migration of skeletal muscle precursor cells. Skeletal muscle 4, 5, doi:10.1186/2044-5040-4-5 (2014).

8 Gengrinovitch, S. et al. Glypican-1 is a VEGF165 binding proteoglycan that acts as an extracellular chaperone for VEGF165. The Journal of biological chemistry 274, 10816-10822 (1999).

9 Filmus, J. \& Capurro, M. The role of glypicans in Hedgehog signaling. Matrix biology : journal of the International Society for Matrix Biology 35, 248-252, doi:10.1016/j.matbio.2013.12.007 (2014).

10 Shiau, C. E., Hu, N. \& Bronner-Fraser, M. Altering Glypican-1 levels modulates canonical Wnt signaling during trigeminal placode development. Developmental biology 348, 107-118, doi:10.1016/j.ydbio.2010.09.017 (2010).

11 David, G. Integral membrane heparan sulfate proteoglycans. FASEB journal : official publication of the Federation of American Societies for Experimental Biology 7, 1023-1030 (1993).

12 Weksberg, R., Squire, J. A. \& Templeton, D. M. Glypicans: a growing trend. Nature genetics 12, 225-227, doi:10.1038/ng0396-225 (1996).

13 Melo, S. A. et al. Glypican-1 identifies cancer exosomes and detects early pancreatic cancer. Nature 523, 177-182, doi:10.1038/nature14581 (2015).

14 Qian, J. Y., Tan, Y. L., Zhang, Y., Yang, Y. F. \& Li, X. Q. Prognostic value of glypican-1 for patients with advanced pancreatic cancer following regional intra-arterial chemotherapy. Oncology letters 16, 1253-1258, doi:10.3892/ol.2018.8701 (2018).

15 Matsuda, K. et al. Glypican-1 is overexpressed in human breast cancer and modulates the mitogenic effects of multiple heparin-binding growth factors in breast cancer cells. Cancer research 61, 5562-5569 (2001).

16 Campbell, D. H. et al. Detection of glypican-1 (GPC-1) expression in urine cell sediments in prostate cancer. PloS one 13, e0196017, doi:10.1371/journal.pone.0196017 (2018).

17 De Robertis, M. et al. Novel insights into Notum and glypicans regulation in colorectal cancer. Oncotarget 6, 41237-41257, doi:10.18632/oncotarget.5652 (2015).

$18 \mathrm{Li}$, J. et al. GPC1 exosome and its regulatory miRNAs are specific markers for the detection and target therapy of colorectal cancer. J Cell Mol Med 21, 838-847, doi:10.1111/jcmm.12941 (2017).

19 Qiao, D., Meyer, K., Mundhenke, C., Drew, S. A. \& Friedl, A. Heparan sulfate proteoglycans as regulators of fibroblast growth factor-2 signaling in brain endothelial cells. Specific role for glypican-1 in glioma angiogenesis. The Journal of biological chemistry 278, 16045-16053, doi:10.1074/jbc.M211259200 (2003).

20 Hara, H. et al. Overexpression of glypican-1 implicates poor prognosis and their chemoresistance in oesophageal squamous cell carcinoma. British journal of cancer 115, 66-75, doi:10.1038/bjc.2016.183 (2016).

21 Chiu, K., Lee, L., Cheung, S. \& Churg, A. M. Glypican-1 immunohistochemistry does not separate mesothelioma from pulmonary adenocarcinoma. Modern pathology : an official journal of the United States and Canadian Academy of Pathology, Inc 31, 1400-1403, doi:10.1038/s41379-0180066-y (2018). 
Amatya, V. J. et al. Glypican-1 immunohistochemistry is a novel marker to differentiate epithelioid mesothelioma from lung adenocarcinoma. Modern pathology : an official journal of the United States and Canadian Academy of Pathology, Inc 31, 809-815, doi:10.1038/modpathol.2017.190 (2018).

$23 \mathrm{Li}$, J. et al. The clinical significance of circulating GPC1 positive exosomes and its regulative miRNAs in colon cancer patients. Oncotarget 8, 101189-101202, doi:10.18632/oncotarget.20516 (2017).

24 Lai, X. et al. A microRNA signature in circulating exosomes is superior to exosomal glypican-1 levels for diagnosing pancreatic cancer. Cancer letters 393, 86-93, doi:10.1016/j.canlet.2017.02.019 (2017).

25 Frampton, A. E. et al. Glypican-1 is enriched in circulating-exosomes in pancreatic cancer and correlates with tumor burden. Oncotarget 9, 19006-19013, doi:10.18632/oncotarget.24873 (2018).

26 Zhou, C. Y. et al. High levels of serum glypican-1 indicate poor prognosis in pancreatic ductal adenocarcinoma. Cancer Med 7, 5525-5533, doi:10.1002/cam4.1833 (2018).

27 Li, J. et al. Glypican-1 antisense transfection modulates TGF-beta-dependent signaling in Colo357 pancreatic cancer cells. Biochemical and biophysical research communications 320, 11481155, doi:10.1016/j.bbrc.2004.06.063 (2004).

28 Harada, E. et al. Glypican-1 targeted antibody-based therapy induces preclinical antitumor activity against esophageal squamous cell carcinoma. Oncotarget 8, 24741-24752, doi:10.18632/oncotarget.15799 (2017).

29 Bauer, M. et al. Heterogeneity of gene expression in stromal fibroblasts of human breast carcinomas and normal breast. Oncogene 29, 1732-1740, doi:10.1038/onc.2009.463 (2010). Xing, F., Saidou, J. \& Watabe, K. Cancer associated fibroblasts (CAFs) in tumor microenvironment. Frontiers in bioscience 15, 166-179, doi:10.2741/3613 (2010).

31 Gassmann, P. \& Haier, J. The tumor cell-host organ interface in the early onset of metastatic organ colonisation. Clinical \& experimental metastasis 25, 171-181, doi:10.1007/s10585-0079130-6 (2008).

32 Gaggioli, C. et al. Fibroblast-led collective invasion of carcinoma cells with differing roles for RhoGTPases in leading and following cells. Nature cell biology 9, 1392-1400, doi:10.1038/ncb1658 (2007).

33 Thomas, V. A. \& Balthasar, J. P. Understanding Inter-Individual Variability in Monoclonal Antibody Disposition. Antibodies (Basel) 8, doi:10.3390/antib8040056 (2019).

34 Maehara, O. et al. Fibroblast growth factor-2-mediated FGFR/Erk signaling supports maintenance of cancer stem-like cells in esophageal squamous cell carcinoma. Carcinogenesis 38, 1073-1083, doi:10.1093/carcin/bgx095 (2017).

35 Harmer, N. J. et al. Towards a resolution of the stoichiometry of the fibroblast growth factor (FGF)-FGF receptor-heparin complex. J Mol Biol 339, 821-834, doi:10.1016/j.jmb.2004.04.031 (2004).

36 Kockeritz, L., Doble, B., Patel, S. \& Woodgett, J. R. Glycogen synthase kinase-3--an overview of an over-achieving protein kinase. Current drug targets 7, 1377-1388, doi:10.2174/1389450110607011377 (2006).

37 Patel, S. \& Woodgett, J. Glycogen synthase kinase-3 and cancer: good cop, bad cop? Cancer cell 14, 351-353, doi:10.1016/j.ccr.2008.10.013 (2008).

38 Erdogan, B. \& Webb, D. J. Cancer-associated fibroblasts modulate growth factor signaling and extracellular matrix remodeling to regulate tumor metastasis. Biochemical Society transactions 45, 229-236, doi:10.1042/BST20160387 (2017). 
Sen, B. \& Johnson, F. M. Regulation of SRC family kinases in human cancers. J Signal Transduct 2011, 865819, doi:10.1155/2011/865819 (2011).

40 Arcaro, A. et al. Critical role for lipid raft-associated Src kinases in activation of PI3K-Akt signalling. Cellular signalling 19, 1081-1092, doi:10.1016/j.cellsig.2006.12.003 (2007).

41 de Diesbach, P. et al. Differential subcellular membrane recruitment of Src may specify its downstream signalling. Experimental cell research 314, 1465-1479, doi:10.1016/j.yexcr.2008.01.015 (2008).

42 Li, X., Brunton, V. G., Burgar, H. R., Wheldon, L. M. \& Heath, J. K. FRS2-dependent SRC activation is required for fibroblast growth factor receptor-induced phosphorylation of Sprouty and suppression of ERK activity. Journal of cell science 117, 6007-6017, doi:10.1242/jcs.01519 (2004).

43 Sandilands, E. et al. Src kinase modulates the activation, transport and signalling dynamics of fibroblast growth factor receptors. EMBO reports 8, 1162-1169, doi:10.1038/sj.embor.7401097 (2007).

44 Ridyard, M. S. \& Robbins, S. M. Fibroblast growth factor-2-induced signaling through lipid raftassociated fibroblast growth factor receptor substrate 2 (FRS2). The Journal of biological chemistry 278, 13803-13809, doi:10.1074/jbc.M210245200 (2003). de Castro, N. P., Rangel, M. C., Nagaoka, T., Salomon, D. S. \& Bianco, C. Cripto-1: an embryonic gene that promotes tumorigenesis. Future oncology 6, 1127-1142, doi:10.2217/fon.10.68 (2010). Klauzinska, M. et al. Cripto-1: an extracellular protein - connecting the sequestered biological dots. Connect Tissue Res 56, 364-380, doi:10.3109/03008207.2015.1077239 (2015).

47 Bianco, C. et al. A Nodal- and ALK4-independent signaling pathway activated by Cripto-1 through Glypican-1 and c-Src. Cancer research 63, 1192-1197 (2003).

48 Park, K. S. et al. High cripto-1 and low miR-205 expression levels as prognostic markers in early stage non-small cell lung cancer. Lung cancer 116, 38-45, doi:10.1016/j.lungcan.2017.12.010 (2018).

$49 \mathrm{Xu}, \mathrm{C}$. et al. Expression of Cripto-1 predicts poor prognosis in stage I non-small cell lung cancer. J Cell Mol Med, doi:10.1111/jcmm.15518 (2020).

50 Richardson, A. M. et al. Vimentin Is Required for Lung Adenocarcinoma Metastasis via Heterotypic Tumor Cell-Cancer-Associated Fibroblast Interactions during Collective Invasion. Clinical cancer research : an official journal of the American Association for Cancer Research 24, 420-432, doi:10.1158/1078-0432.CCR-17-1776 (2018).

51 Gaggioli, C. Collective invasion of carcinoma cells: when the fibroblasts take the lead. Cell adhesion \& migration 2, 45-47, doi:10.4161/cam.2.1.5705 (2008).

52 Cicchini, C. et al. TGFbeta-induced EMT requires focal adhesion kinase (FAK) signaling. Experimental cell research 314, 143-152, doi:10.1016/j.yexcr.2007.09.005 (2008).

53 Canel, M. et al. Quantitative in vivo imaging of the effects of inhibiting integrin signaling via Src and FAK on cancer cell movement: effects on E-cadherin dynamics. Cancer research 70, 94139422, doi:10.1158/0008-5472.CAN-10-1454 (2010).

54 Zhou, Q., Guo, X. \& Choksi, R. Activation of Focal Adhesion Kinase and Src Mediates Acquired Sorafenib Resistance in A549 Human Lung Adenocarcinoma Xenografts. The Journal of pharmacology and experimental therapeutics 363, 428-443, doi:10.1124/jpet.117.240507 (2017).

55 Hamburger, A. W. \& Salmon, S. E. Primary bioassay of human tumor stem cells. Science 197, 461-463, doi:10.1126/science.560061 (1977). 
56 Slocum, H. K., Malmberg, M., Greco, W. R., Parsons, J. C. \& Rustum, Y. M. The determination of growth rates of individual colonies in agarose using high-resolution automated image analysis. Cytometry 11, 793-804, doi:10.1002/cyto.990110705 (1990).

57 Berger, D. P., Henss, H., Winterhalter, B. R. \& Fiebig, H. H. The clonogenic assay with human tumor xenografts: evaluation, predictive value and application for drug screening. Annals of oncology : official journal of the European Society for Medical Oncology / ESMO 1, 333-341, doi:10.1093/oxfordjournals.annonc.a057770 (1990).

58 Guzman, C., Bagga, M., Kaur, A., Westermarck, J. \& Abankwa, D. ColonyArea: an ImageJ plugin to automatically quantify colony formation in clonogenic assays. PloS one 9, e92444, doi:10.1371/journal.pone.0092444 (2014).

59 Weiss, I. D. et al. In the hunt for therapeutic targets: mimicking the growth, metastasis, and stromal associations of early-stage lung cancer using a novel orthotopic animal model. Journal of thoracic oncology : official publication of the International Association for the Study of Lung Cancer 10, 46-58, doi:10.1097/JTO.0000000000000367 (2015). 


\section{Figure Legends}

Figure 1. Determination of cytotoxicity of anti-GPC1 mAb in 2D A549, H460 and CCD-19Lu monocultures and 3D A549, H460, A549/CCD-19Lu and H460/CCD-19Lu spheroids. A-C, Concentration-effect curves for anti-GPC1 mAb and mouse IgG isotype treatment in (A) A549 and (B) H460 human NSCLC cells and (C) CCD-19Lu human lung fibroblasts. Results are presented as mean \pm standard deviation (SD) $(\mathrm{N}=4) .{ }^{* *} p<0.01$ compared with anti-GPC1 $\mathrm{mAb}$ treated $\mathrm{H} 460$ cells using one-way analysis of variance (ANOVA) followed by Tukey-Kramer post hoc multiple comparison test. D-E, Concentration-effect curves for anti-GPC1 mAb treatment in (D) A549 and A549/CCD-19Lu spheroids and (E) H460 and H460/CCD-19Lu spheroids. Results are presented as mean $\pm \mathrm{SD}(\mathrm{N}=3)$. Error bars represent the inter-assay SD. ${ }^{* *} p<0.01$ compared with the corresponding monoculture counterpart using independent two-sample $t$ test.

Figure 2. Soft agar colony formation assay for assessing the effect of anti-GPC1 mAb on the anchorage-independent growth of A549 and H460 NSCLC cells after treatment with increasing concentrations of anti-GPC1 mAb. Colonies $>0.1 \mathrm{~mm}$ were counted using ImageJ software. Independent experiments were performed in quadruplicates $(\mathrm{N}=4)$ with $2 \times 10 \mathrm{E} 3 \mathrm{cells} /$ well plated in a 24-well plate for the assay. Colonies were analyzed after 10 12 days of culture and stained with $1 \mathrm{mg} / \mathrm{ml}$ of MTT. A, Representative images of colony formation of each cell line from one experiment are presented. B, Quantitative analyses of colony formation and anchorage-independent growth based on the relative number of colonies and percent of colony area, respectively. Results were presented as the mean $\pm S D(N=4)$. ${ }^{*} p<0.05$ and ${ }^{* *} p<0.01$ compared among vehicle, mouse lgG isotype and individual anti-GPC1-mAb treatment groups in the same cell line using one-way ANOVA followed by Tukey-Kramer post hoc multiple comparison test.

Figure 3. Evaluation of the anti-invasive effect of anti-GPC1 mAb using the 3D spheroid invasion assay. Cell-covered area was quantified using ImageJ and expressed as the fold change in area relative to Day 0. Daily micrographs showing the invasion progress of (A) A549 monoculture spheroids, (B) H460 monoculture spheroids, (C) A549 coculture spheroids and (D) $\mathrm{H} 460$ coculture spheroids. Original magnifications, $\times 100$. Error bars represent the SD of the mean from eight independent experiments $(N=4)$. Results are presented as mean $\pm \mathrm{SD}$. ${ }^{*} p<$ 0.05 and ${ }^{* *} p<0.05$ compared among vehicle, mouse IgG isotype and individual anti-GPC1$\mathrm{mAb}$ treatment groups using one-way ANOVA followed by Tukey-Kramer post hoc multiple comparison test.

Figure 4. Densitometric analysis of Western blot results demonstrating the effect of anti-GPC1 $\mathrm{mAb}$ on the expression levels of selected EMT markers and effector proteins common to the GPC1-facilitated growth factor signal transduction pathways, including MEK/ERK/RSK, AKT/GSK3/mTOR, Src/FAK pathways in CCD-19Lu lung fibroblasts that were cultured either as (A) monocultures or in indirect co-culture with (B) H460 or (C) A549 NSCLC cells and in (D) A549 cells that were cultured in indirect co-culture with CCD-19Lu lung fibroblasts. Cell monocultures or co-cultures were treated with vehicle (i.e., PBS), $100 \mu \mathrm{g} / \mathrm{ml}$ mouse IgG isotype and $100 \mu \mathrm{g} / \mathrm{ml}$ anti-GPC1-mAb for 24 hours. Whole cell lysate samples were subjected to Western blot analysis (30 $\mu \mathrm{g}$ of protein per lane). Detection of $\beta$-actin was used to ensure equal sample loading per lane. Relative immunoreactive band intensities are expressed as percent change over the average signal value in the vehicle-treated cells. For phosphorylated proteins, results are expressed as the ratio of phosphorylated-to-total species relative to the vehicle control cells. Data are representative of three independent experiments $(N=3)$ and presented as mean \pm SD. SD is denoted by the error bars. ${ }^{*} p<0.05$ and ${ }^{* *} p<0.01$ compared among vehicle, $100 \mu \mathrm{g} / \mathrm{ml}$ mouse IgG isotype and $100 \mu \mathrm{g} / \mathrm{ml}$ anti-GPC1-mAb in the same cell line using one-way ANOVA followed by Tukey-Kramer post hoc multiple comparison test. 
Figure 5. Assessment of the growth of established orthotopic A549 lung tumors in response to anti-GPC1 mAb treatment. A, Bioluminescence imaging conducted once a week over the 24 days of treatment period during which the tumor bearing athymic nude mice were given tail-vein injections of vehicle control $(\mathrm{N}=5)$, or $10 \mathrm{mg} / \mathrm{kg}$ mouse $\mathrm{lgG}$ isotype $(\mathrm{N}=7)$, or $10 \mathrm{mg} / \mathrm{kg}$ of antiGPC1 mAb $(N=7)$ once every 72 hours for a total of 8 doses. $\mathbf{B}$, Tumor growth rate was determined from serial measurements of tumor volume obtained from BLI photon counts. A nonparametric Kruskal-Wallis test was used to compare the tumor growth rate among control, mouse IgG isotype and anti-GPC1 mAb groups, and no statistically significant difference was found among the three study groups $(p>0.05)$. C, No significant difference in total lung weights that reflect the lung tumor burden was found among three study groups using one-way ANOVA followed by Tukey-Kramer post hoc multiple comparison test $(p>0.05)$. Data are presented as mean $\pm S D$. SD is denoted by the error bars.

Figure 6. Assessment of orthotopic A549 lung tumor growth in response to intraperitoneal administration of anti-GPC1 $\mathrm{mAb}$ at the dose level of 1,10 and $50 \mathrm{mg} / \mathrm{kg}$. Two weeks after orthotopic inoculation of A549 tumor cells, athymic nude mice received the intraperitoneal injections of PBS (vehicle) or anti-GPC1 $\mathrm{mAb}$ at 1,10 and $50 \mathrm{mg} / \mathrm{kg}$ once a week for 3 doses and then once every 10 days for 2 more doses. A, Bioluminescence imaging performed a week after the last dose of anti-GPC1 mAb showed that bioluminescence signals were detected in 6 out of 7 (6/7), 6/8, 4/8, and 6/7 animals in the vehicle control, $1 \mathrm{mg} / \mathrm{kg}, 10 \mathrm{mg} / \mathrm{kg}$ and $50 \mathrm{mg} / \mathrm{kg}$ anti-GPC1mAb groups, respectively. B, Anti-GPC1 mAb plasma levels on the final day of the experiment determined by ELICA showed a dose-dependent increase in the anti-GPC1 mAb plasma levels. Data are presented as mean $\pm S D$ ( $N=6$ for each study group). SD is denoted by the error bars. ${ }^{*} p<0.05$ and ${ }^{* *} p<0.01$ compared among vehicle control, 1,10 and 50 $\mathrm{mg} / \mathrm{kg}$ anti-GPC1 mAb groups using one-way ANOVA followed by Tukey-Kramer post hoc multiple comparison test. $\mathbf{C}$, No significant difference in total lung weights that reflect the lung tumor burden was found among the four study groups using one-way ANOVA followed by Tukey-Kramer post hoc multiple comparison test $(p>0.05)$. Data are presented as mean \pm SD. $\mathrm{SD}$ is denoted by the error bars.

Figure 7. Densitometric analysis of Western blot results demonstrating the effect of anti-GPC1 $\mathrm{mAb}$ on the expression levels of selected EMT markers and effectors proteins common to the GPC1-facilitated signaling transduction, including MEK/ERK/RSK, AKT/GSK3/mTOR, Src/FAK signaling pathways in paired (A) A549 lung tumor xenografts and (B) adjacent noncancerous lung tissue samples. Tumor and adjacent normal lung tissue samples were collected from athymic nude mice bearing established orthotopic A549 lung tumor and receiving IV administration of vehicle control $(\mathrm{N}=5), 10 \mathrm{mg} / \mathrm{kg}$ mouse $\mathrm{lgG}$ isotype $(\mathrm{N}=7)$, and $10 \mathrm{mg} / \mathrm{kg}$ anti-GPC1 mAb $(\mathrm{N}=6)$ once every 72 hours for a total of 8 doses. Tumor and lung tissue homogenate samples were subjected to Western blot analysis ( $80 \mu \mathrm{g}$ of protein per lane). Detection of $\beta$-actin was used to ensure equal sample loading per lane. Relative immunoreactive band intensities are expressed as percent change over the average signal value in the vehicle-treated lung or tumor tissues. For phosphorylated proteins, results are expressed as the ratio of phosphorylated-to-total species relative to the vehicle control. Data are presented as mean \pm SD. SD is denoted by the error bars. No statistically significant difference was found among the three study groups $(p>0.05)$.

Figure 8. Densitometric analysis of Western blot results demonstrating the effect of anti-GPC1 $\mathrm{mAb}$ on the expression levels of selected EMT markers, GPC1-facilitated FGF2 activated FGFR1 downstream signaling pathways in paired A549 lung tumor xenografts $(\mathbf{A}-\mathbf{C})$ and adjacent normal lung tissue samples (D-F). Athymic nude mice received IP administration of vehicle control, 1,10 or $50 \mathrm{mg} / \mathrm{kg}$ of anti-GPC1 mAb two week after the orthotopic inoculation of A549 tumor cells. Each treatment was given to individual animals once a week for 3 doses and 
then once every 10 days for 2 more doses for a total of 8 doses. Tumor and lung tissue homogenate samples were subjected to Western blot analysis ( $80 \mu \mathrm{g}$ of protein per lane). Detection of $\beta$-actin was used to ensure equal sample loading per lane. Relative immunoreactive band intensities are expressed as percent change over the average signal value in the vehicle-treated lung or tumor tissues. For phosphorylated proteins, results are expressed as the ratio of phosphorylated-to-total species relative to the vehicle control. Data are presented as mean $\pm \mathrm{SD}$ ( $N=6$ for each study group). SD is denoted by the error bars. * $\mathrm{p}<$ 0.05 and ${ }^{* *} \mathrm{p}<0.01$ compared among vehicle control, 1,10 and $50 \mathrm{mg} / \mathrm{kg}$ anti-GPC1 mAb groups using one-way ANOVA followed by Tukey-Kramer post hoc multiple comparison test.

Figure 9. Schematic presentation of the proposed mechanism by which anti-GPC1 mAb impairs the GPC1-facilitated encounter of growth factors with receptors that requires the Y416 phosphorylation of Src and recruitment of active Src onto the plasma membrane to initiate the signal transduction, leading to the attenuation of downstream MEK/ERK/RSK signaling pathway. 
Figure 1.
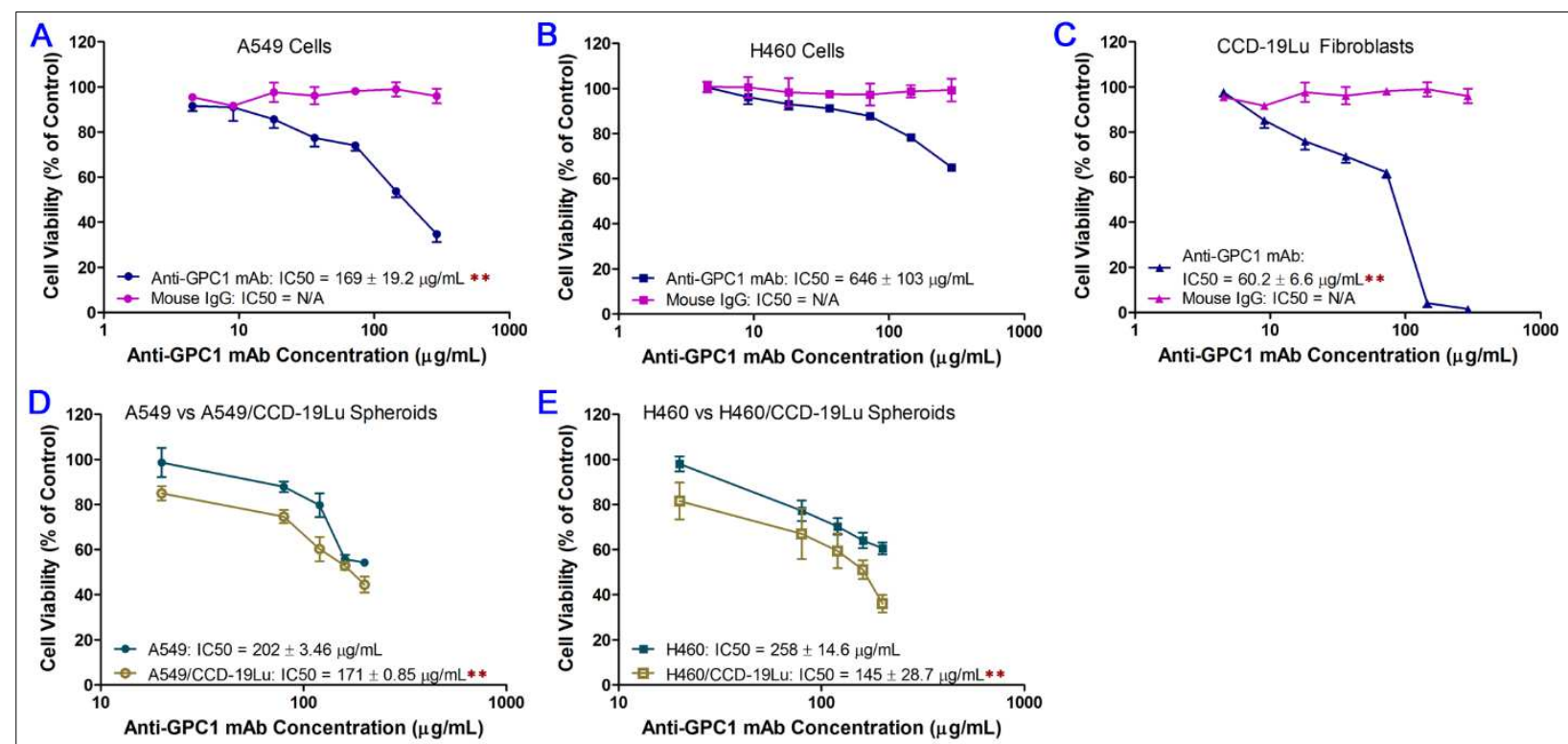
Figure 2.

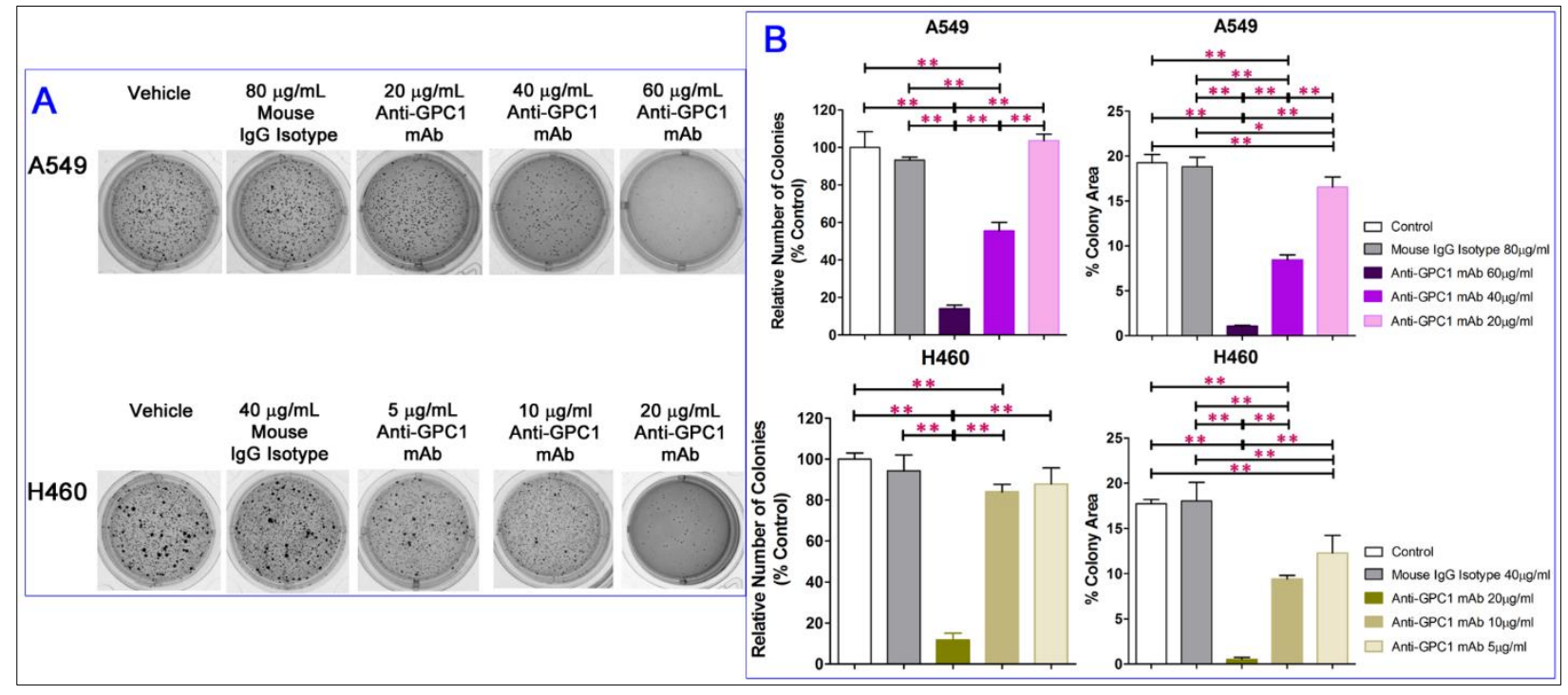


Figure 3. 


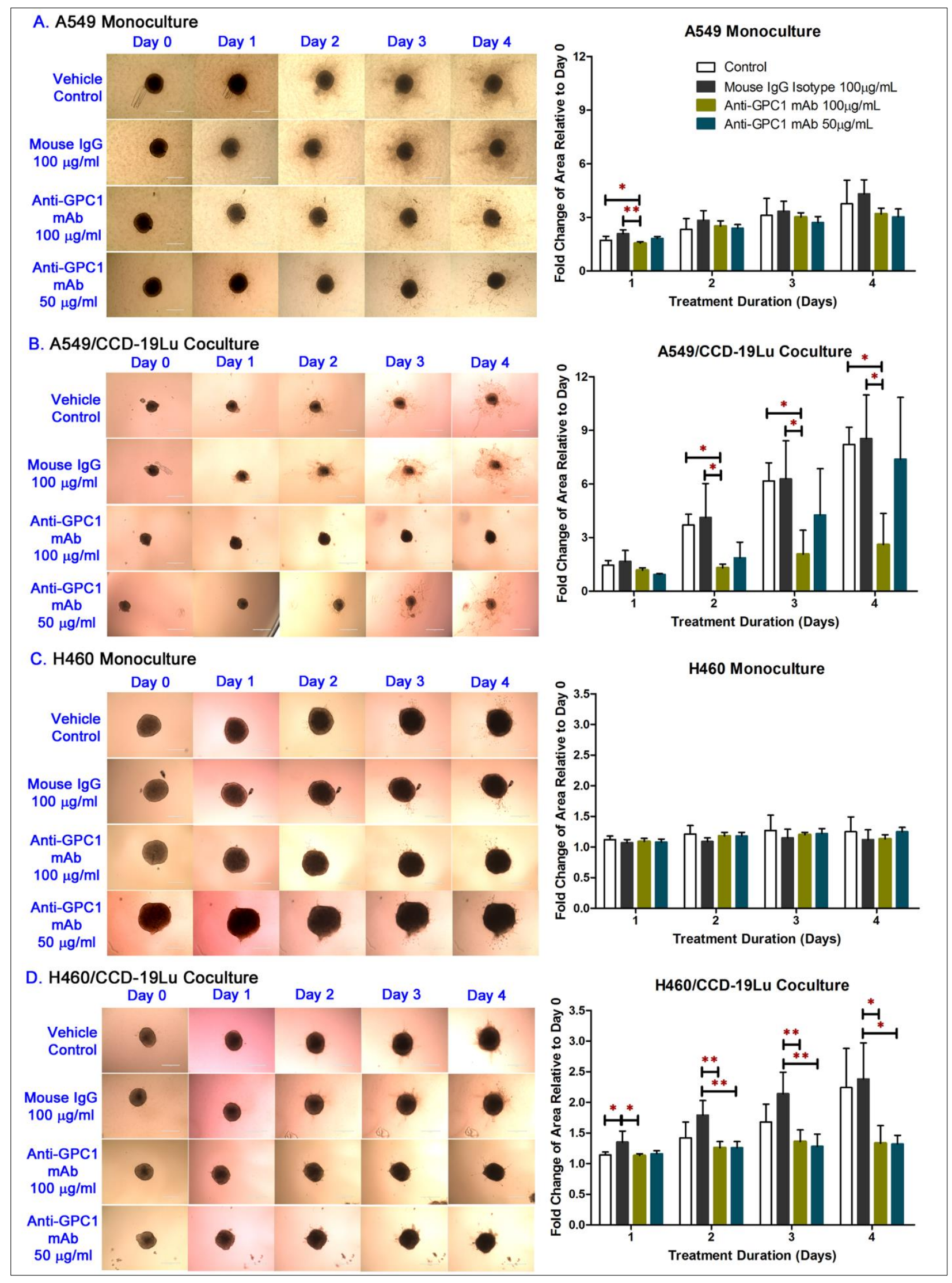


Figure 4.

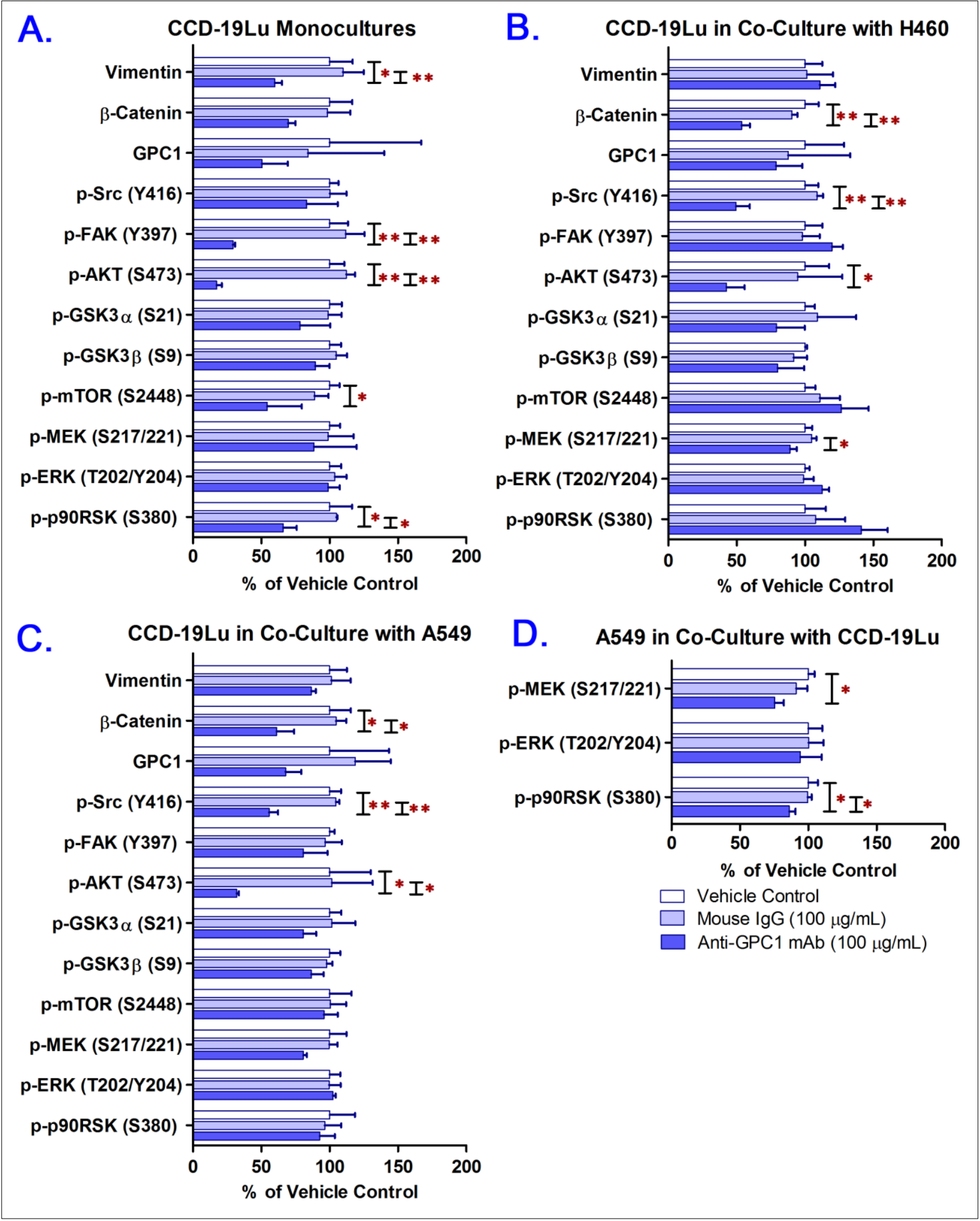


Figure 5.

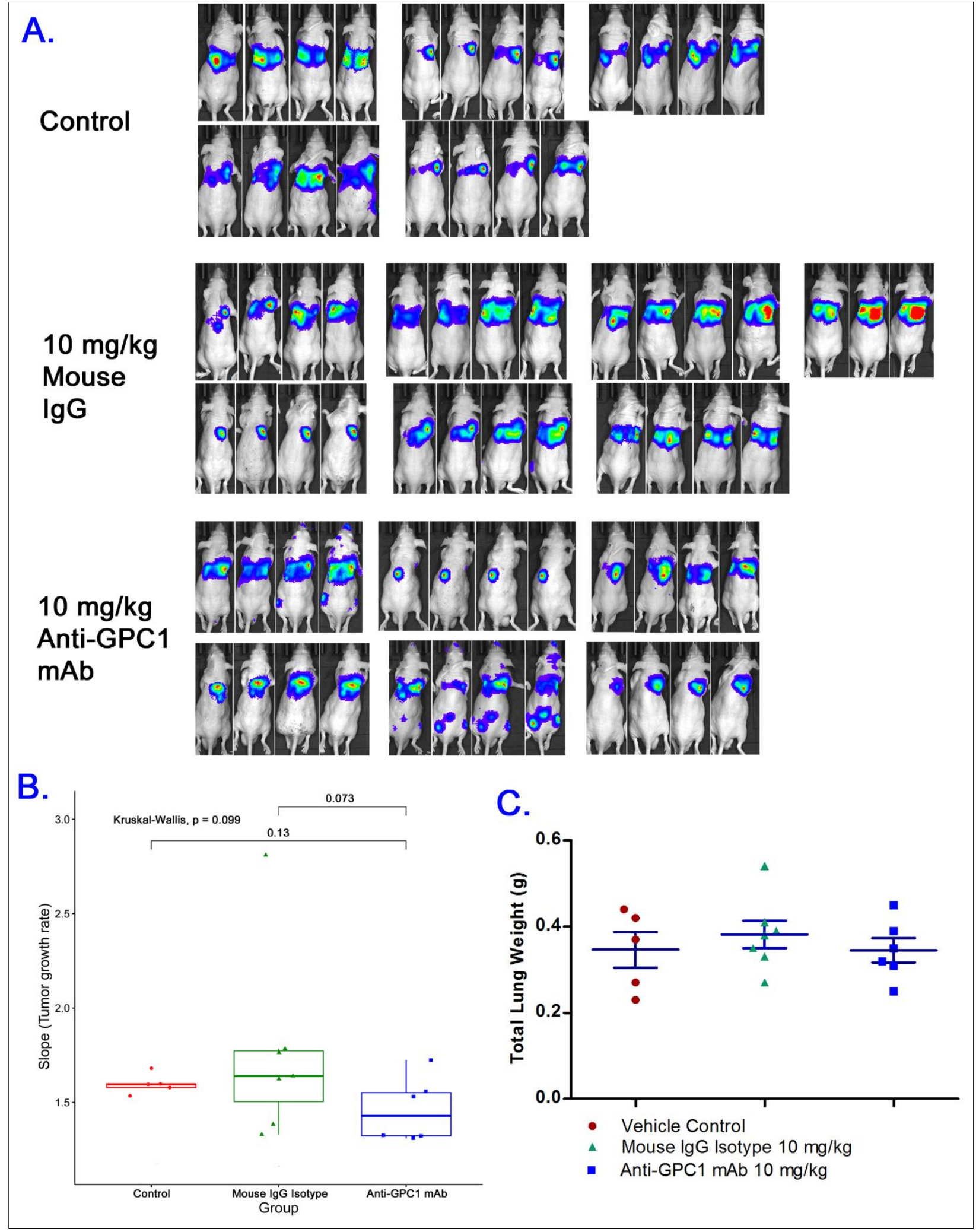


Figure 6.

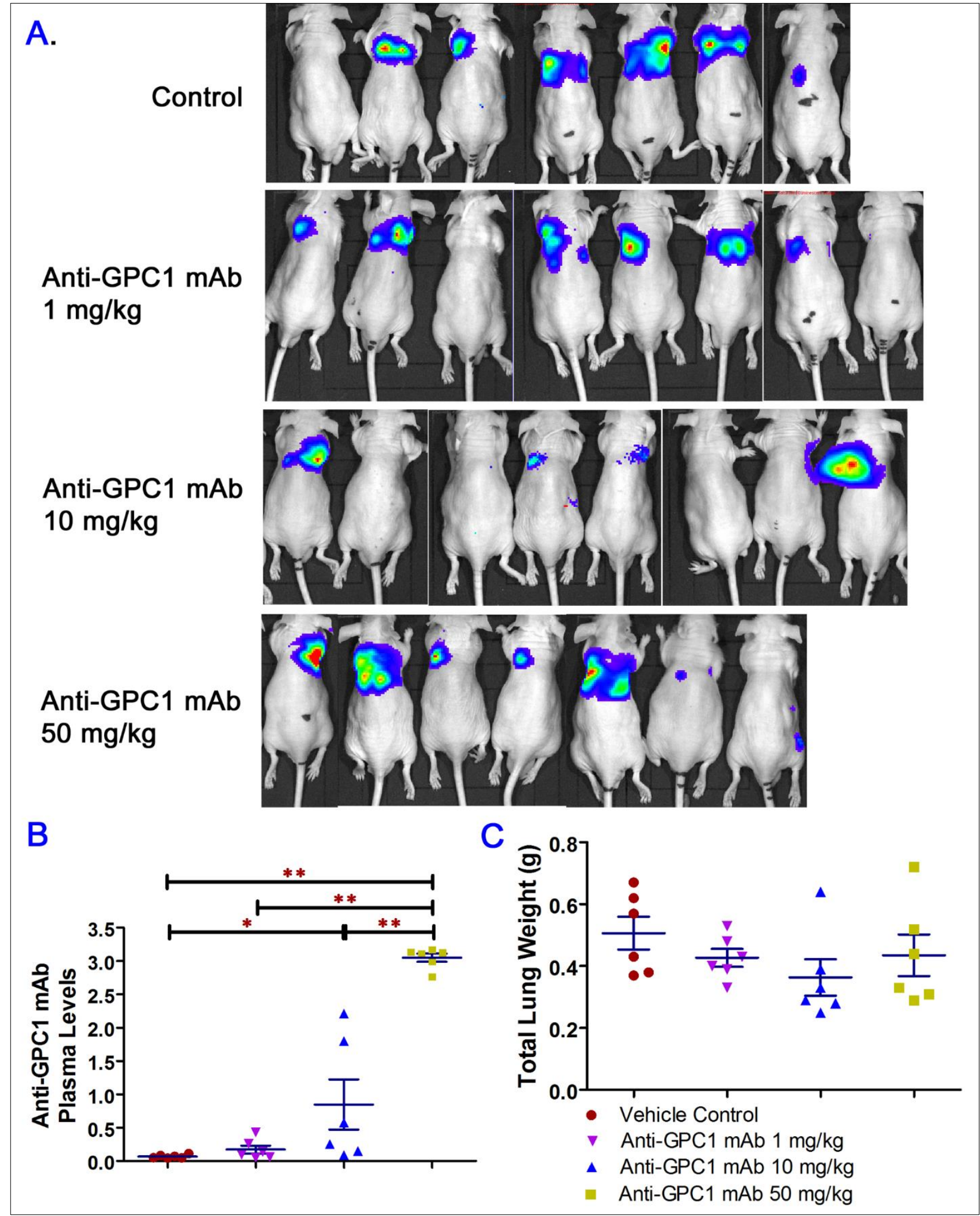


Figure 7.

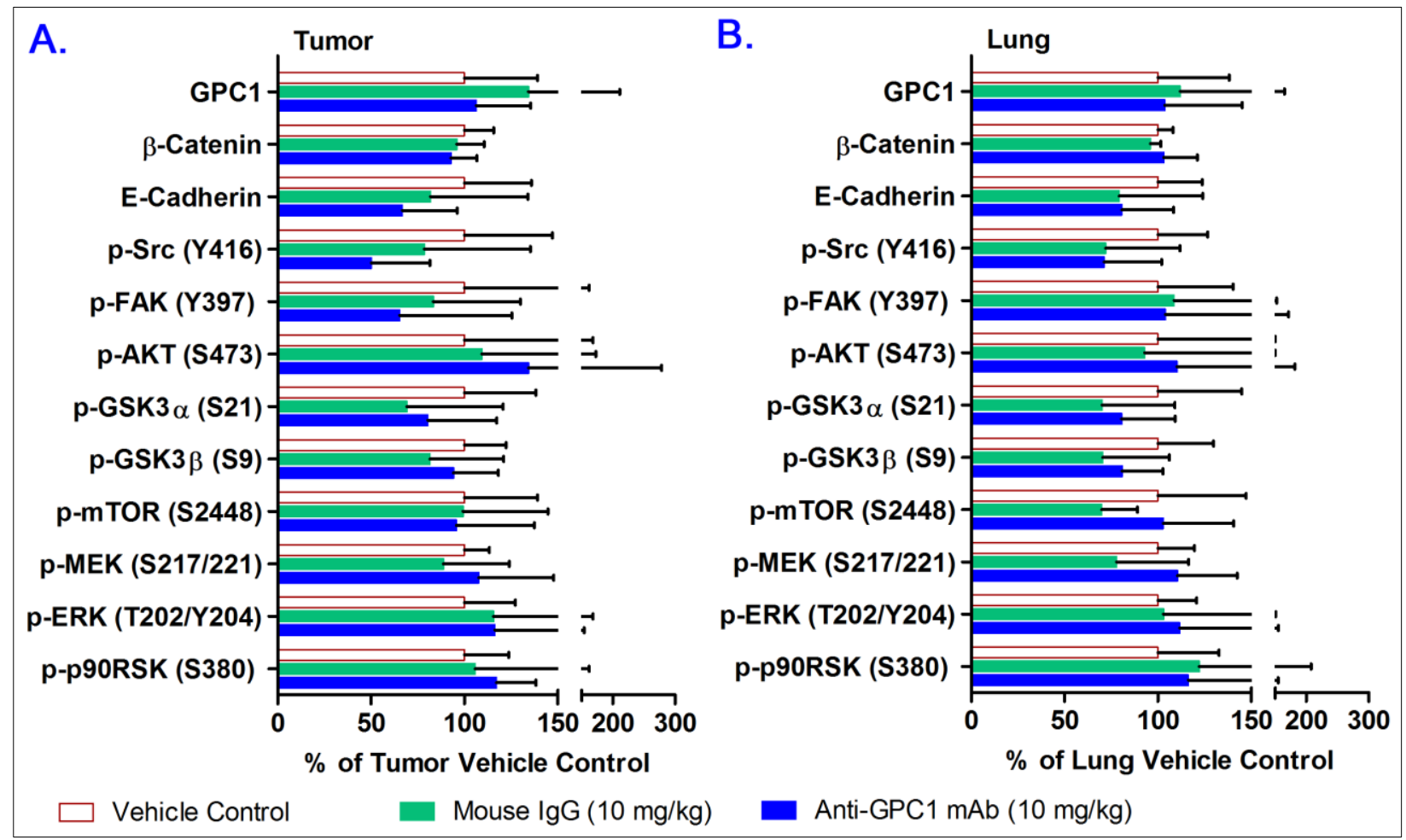


Figure 8.

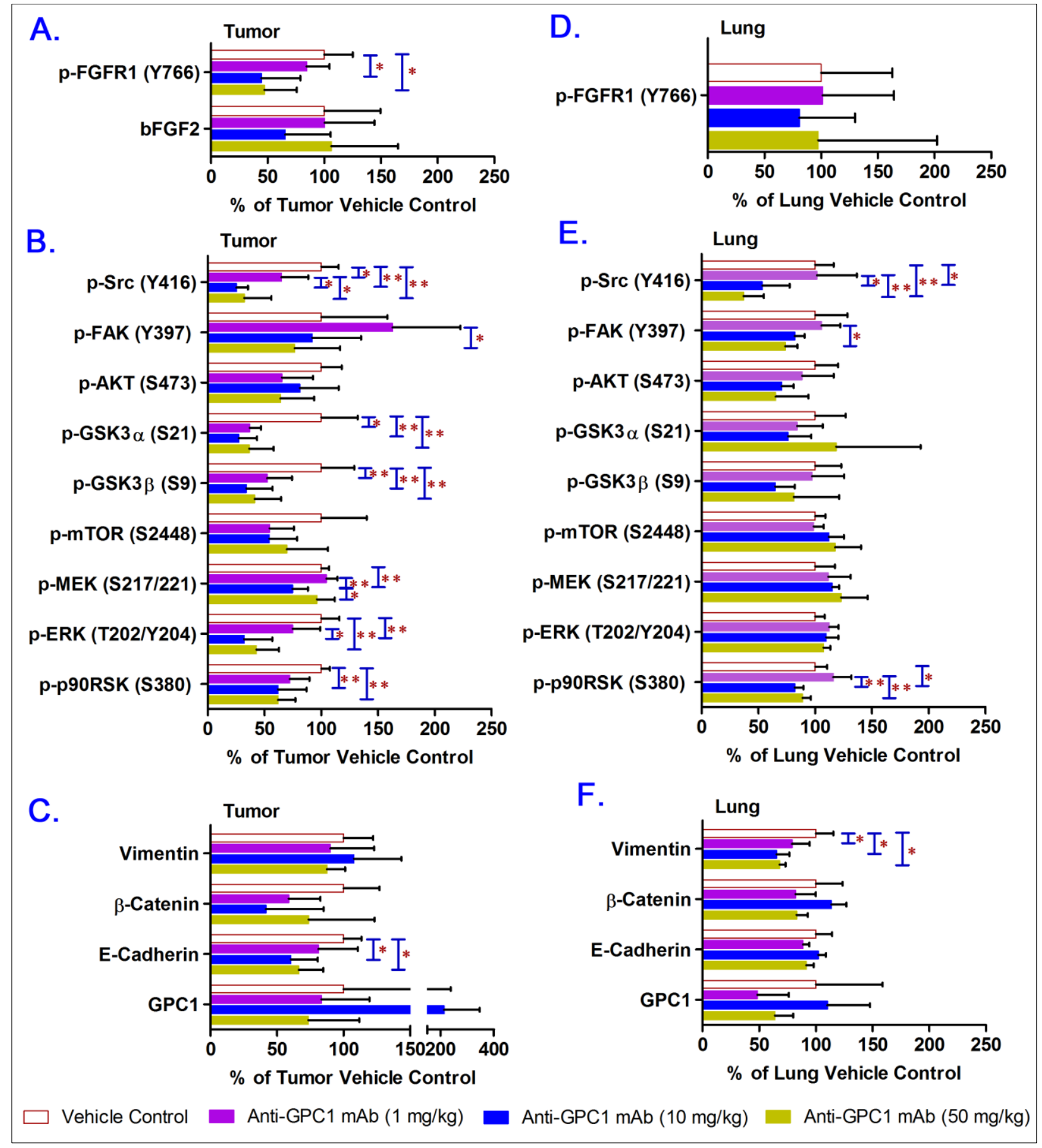


Figure 9.

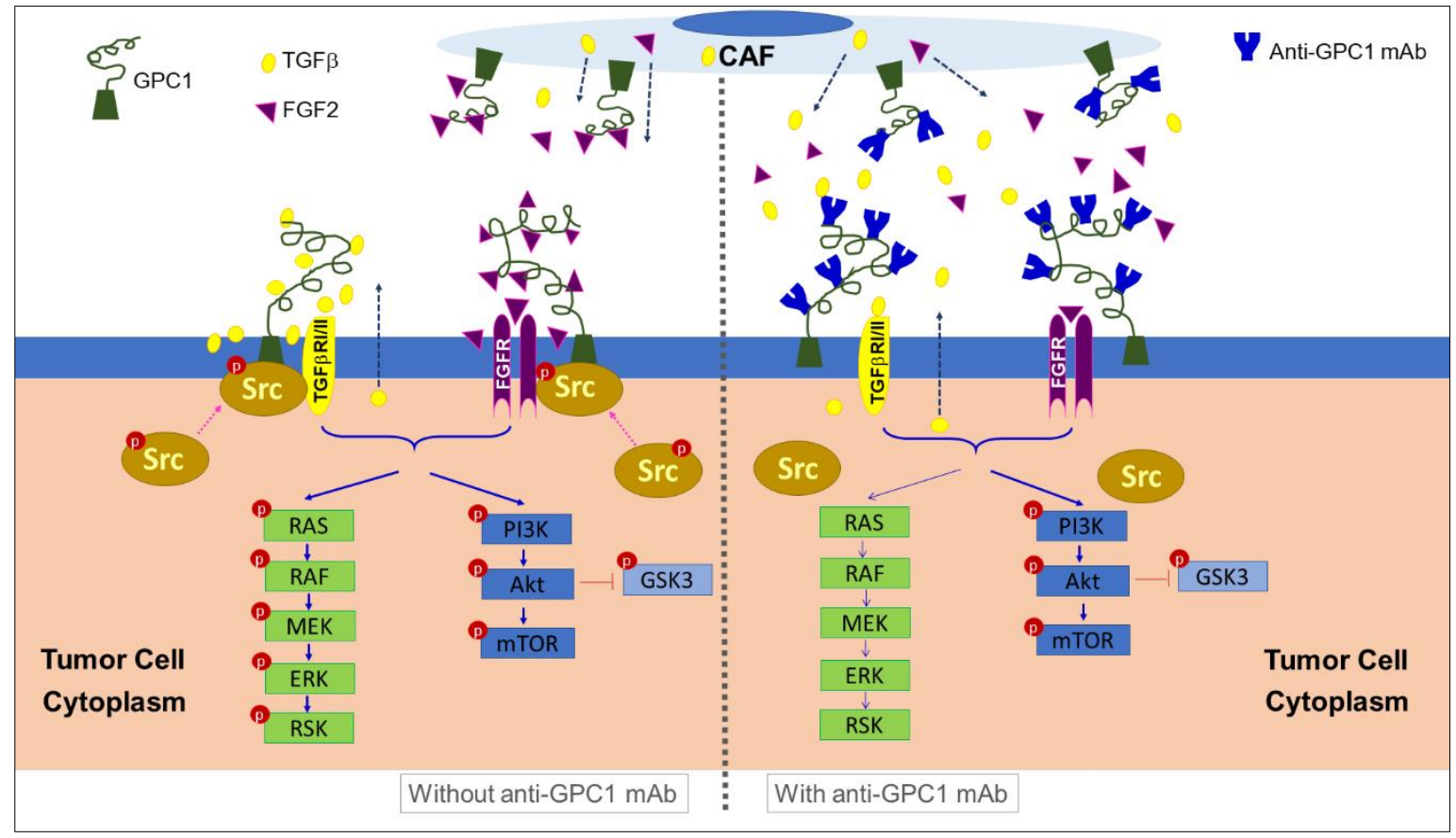




\section{Figures}

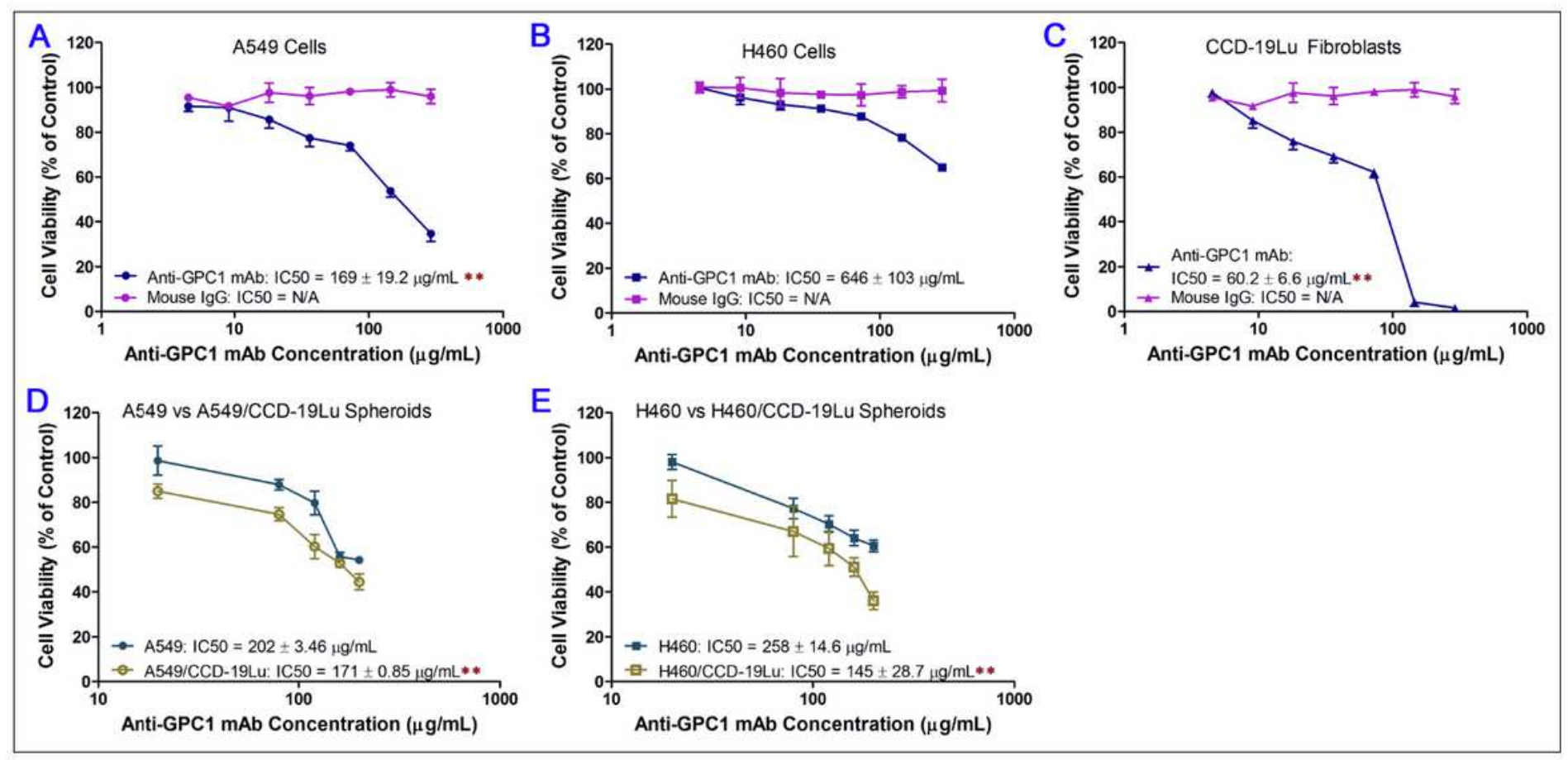

Figure 1

Determination of cytotoxicity of anti-GPC1 mAb in 2D A549, H460 and CCD-19Lu monocultures and 3D A549, H460, A549/CCD-19Lu and H460/CCD-19Lu spheroids. A-C, Concentration-effect curves for antiGPC1 mAb and mouse IgG isotype treatment in (A) A549 and (B) H460 human NSCLC cells and (C) CCD19 Lu human lung fibroblasts. Results are presented as mean \pm standard deviation $(S D)(N=4)$. ${ }^{* \star} p<$ 0.01 compared with anti-GPC1 mAb treated $\mathrm{H} 460$ cells using one-way analysis of variance (ANOVA) followed by Tukey-Kramer post hoc multiple comparison test. D-E, Concentration-effect curves for antiGPC1 mAb treatment in (D) A549 and A549/CCD-19Lu spheroids and (E) H460 and H460/CCD-19Lu spheroids. Results are presented as mean $\pm S D(N=3)$. Error bars represent the inter-assay SD. ${ }^{* \star} p<0.01$ compared with the corresponding monoculture counterpart using independent two-sample t test. 


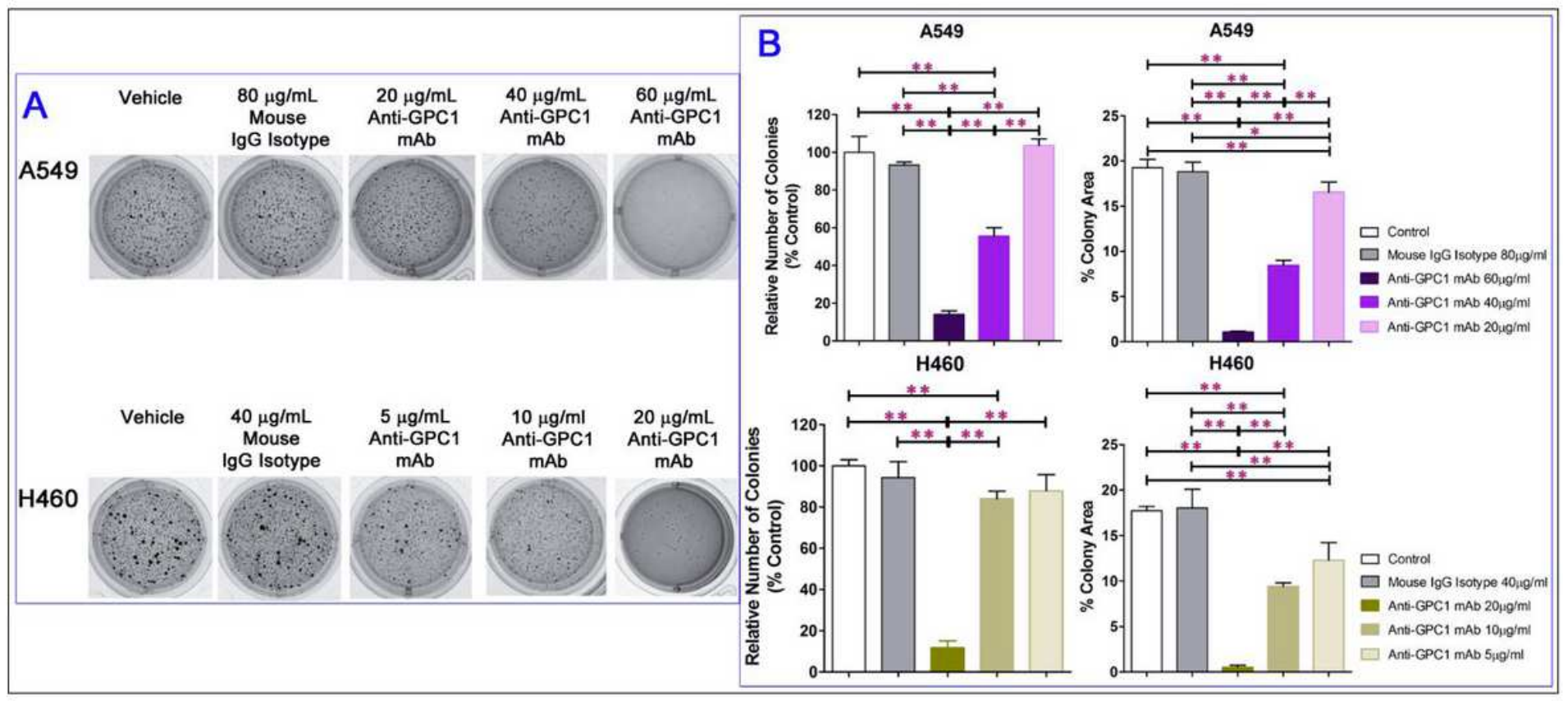

Figure 2

Soft agar colony formation assay for assessing the effect of anti-GPC1 mAb on the anchorageindependent growth of A549 and H460 NSCLC cells after treatment with increasing concentrations of anti-GPC1 mAb. Colonies $>0.1 \mathrm{~mm}$ were counted using Image J software. Independent experiments were performed in quadruplicates $(\mathrm{N}=4)$ with $2 \times 10 \mathrm{E} 3$ cells/well plated in a 24-well plate for the assay. Colonies were analyzed after 10 12 days of culture and stained with $1 \mathrm{mg} / \mathrm{ml}$ of MTT. A, Representative images of colony formation of each cell line from one experiment are presented. B, Quantitative analyses of colony formation and anchorage-independent growth based on the relative number of colonies and percent of colony area, respectively. Results were presented as the mean $\pm S D(N=4)$. ${ }^{\star} p<0.05$ and ${ }^{* *} p<$ 0.01 compared among vehicle, mouse IgG isotype and individual anti-GPC1-mAb treatment groups in the same cell line using one-way ANOVA followed by Tukey-Kramer post hoc multiple comparison test. 


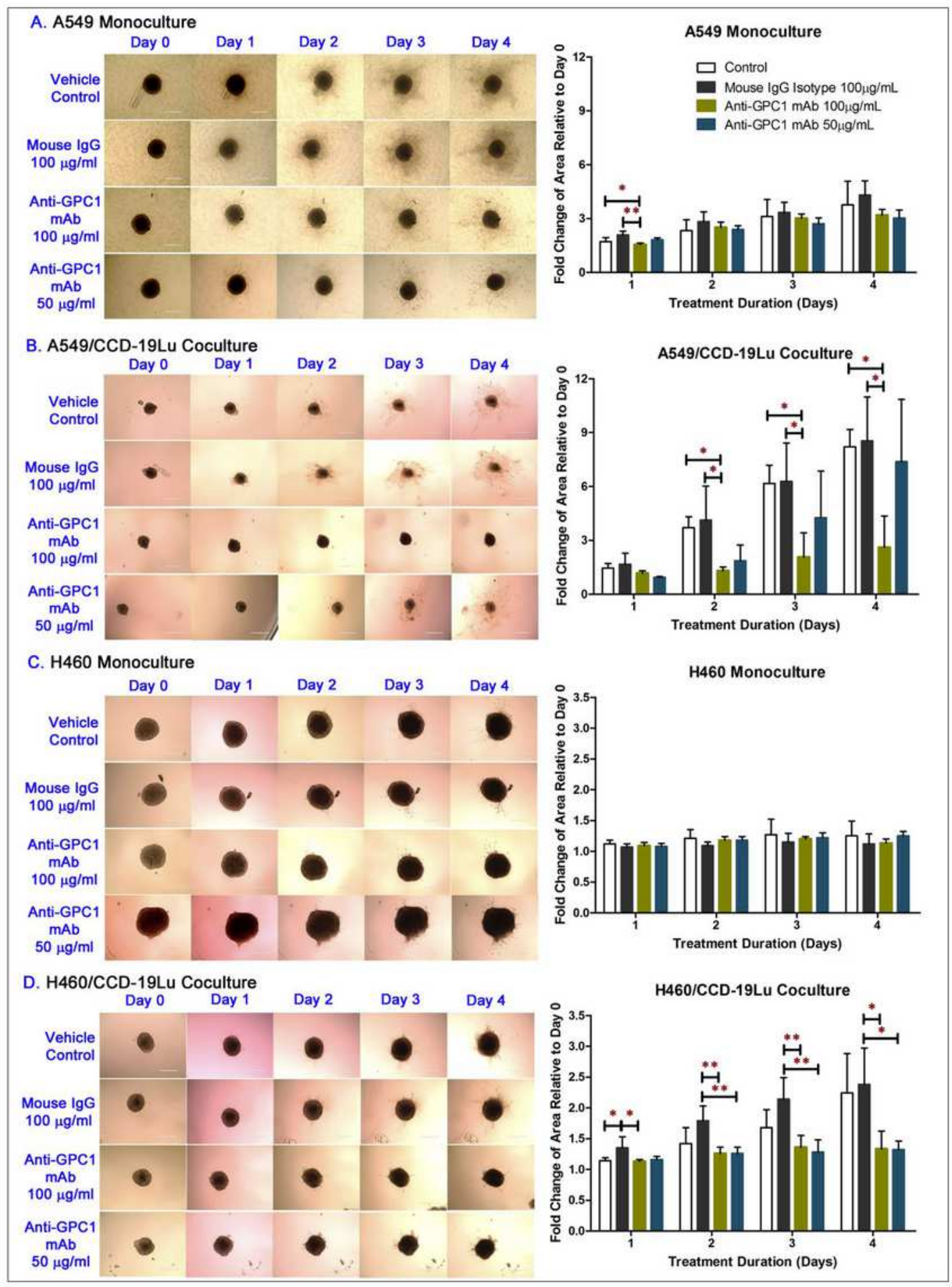

Figure 3

Evaluation of the anti-invasive effect of anti-GPC1 mAb using the 3D spheroid invasion assay. Cellcovered area was quantified using Image $J$ and expressed as the fold change in area relative to Day 0. Daily micrographs showing the invasion progress of (A) A549 monoculture spheroids, (B) H460 monoculture spheroids, (C) A549 coculture spheroids and (D) H460 coculture spheroids. Original magnifications, $\times 100$. Error bars represent the SD of the mean from eight independent experiments $(\mathrm{N}=$ 
4). Results are presented as mean \pm SD. ${ }^{*} p<0.05$ and ${ }^{* *} p<0.05$ compared among vehicle, mouse IgG isotype and individual anti-GPC1-mAb treatment groups using one-way ANOVA followed by Tukey-Kramer post hoc multiple comparison test.

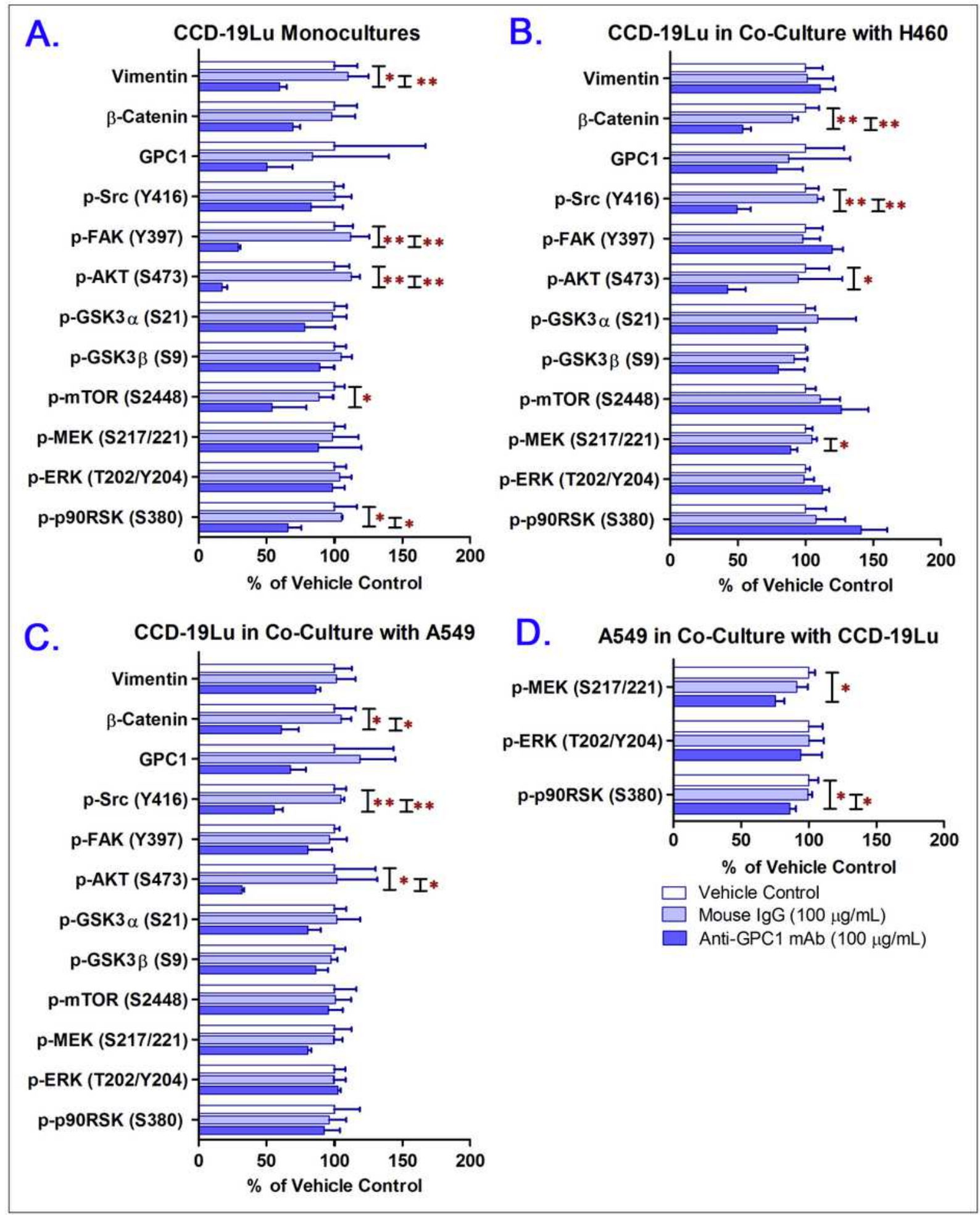

Figure 4

Densitometric analysis of Western blot results demonstrating the effect of anti-GPC1 mAb on the expression levels of selected EMT markers and effector proteins common to the GPC1-facilitated growth 
factor signal transduction pathways, including MEK/ERK/RSK, AKT/GSK3/mTOR, Src/FAK pathways in CCD-19Lu lung fibroblasts that were cultured either as (A) monocultures or in indirect co-culture with (B) H460 or (C) A549 NSCLC cells and in (D) A549 cells that were cultured in indirect co-culture with CCD$19 \mathrm{Lu}$ lung fibroblasts. Cell monocultures or co-cultures were treated with vehicle (i.e., PBS), $100 \mu \mathrm{g} / \mathrm{ml}$ mouse IgG isotype and $100 \mu \mathrm{g} / \mathrm{ml}$ anti-GPC1-mAb for 24 hours. Whole cell lysate samples were subjected to Western blot analysis ( $30 \mu \mathrm{g}$ of protein per lane). Detection of $\beta$-actin was used to ensure equal sample loading per lane. Relative immunoreactive band intensities are expressed as percent change over the average signal value in the vehicle-treated cells. For phosphorylated proteins, results are expressed as the ratio of phosphorylated-to-total species relative to the vehicle control cells. Data are representative of three independent experiments $(\mathrm{N}=3)$ and presented as mean $\pm S D$. SD is denoted by the error bars. * $p$ 0.05 and ${ }^{*} \mathrm{p}<0.01$ compared among vehicle, $100 \mu \mathrm{g} / \mathrm{ml}$ mouse $\mathrm{lgG}$ isotype and $100 \mu \mathrm{g} / \mathrm{ml}$ anti-GPC1$\mathrm{mAb}$ in the same cell line using one-way ANOVA followed by Tukey-Kramer post hoc multiple comparison test. 


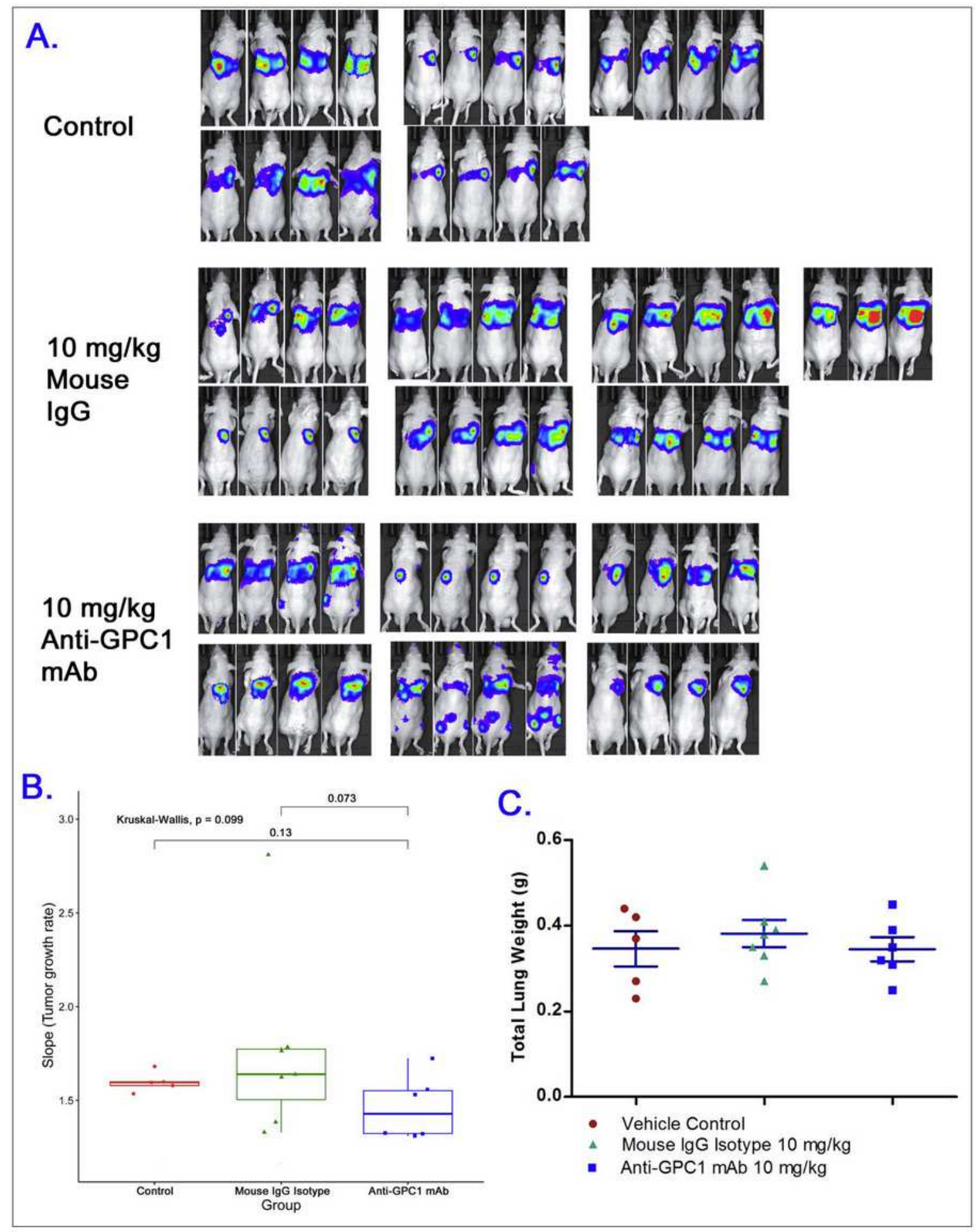

Figure 5

Assessment of the growth of established orthotopic A549 lung tumors in response to anti-GPC1 mAb treatment. A, Bioluminescence imaging conducted once a week over the 24 days of treatment period during which the tumor bearing athymic nude mice were given tail-vein injections of vehicle control $(\mathrm{N}=$ $5)$, or $10 \mathrm{mg} / \mathrm{kg}$ mouse lgG isotype ( $\mathrm{N}=7)$, or $10 \mathrm{mg} / \mathrm{kg}$ of anti-GPC1 mAb ( $\mathrm{N}=7)$ once every 72 hours for a total of 8 doses. B, Tumor growth rate was determined from serial measurements of tumor volume 
obtained from BLI photon counts. A nonparametric Kruskal-Wallis test was used to compare the tumor growth rate among control, mouse IgG isotype and anti-GPC1 mAb groups, and no statistically significant difference was found among the three study groups ( $p>0.05$ ). C, No significant difference in total lung weights that reflect the lung tumor burden was found among three study groups using one-way ANOVA followed by Tukey-Kramer post hoc multiple comparison test $(p>0.05)$. Data are presented as mean \pm SD. SD is denoted by the error bars.

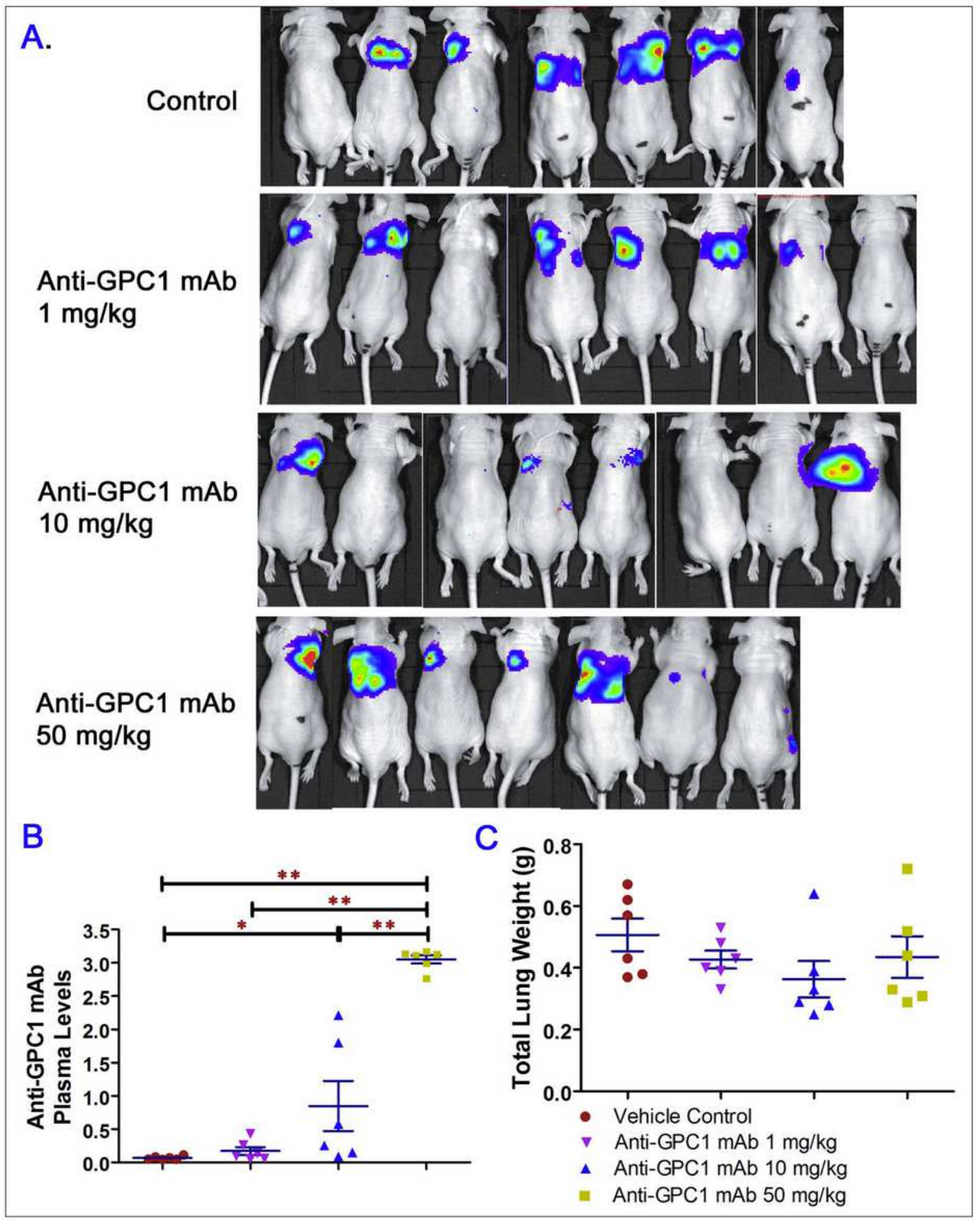

Figure 6 
Assessment of orthotopic A549 lung tumor growth in response to intraperitoneal administration of antiGPC1 mAb at the dose level of 1, 10 and $50 \mathrm{mg} / \mathrm{kg}$. Two weeks after orthotopic inoculation of A549 tumor cells, athymic nude mice received the intraperitoneal injections of PBS (vehicle) or anti-GPC1 mAb at 1,10 and $50 \mathrm{mg} / \mathrm{kg}$ once a week for 3 doses and then once every 10 days for 2 more doses. A, Bioluminescence imaging performed a week after the last dose of anti-GPC1 mAb showed that bioluminescence signals were detected in 6 out of $7(6 / 7), 6 / 8,4 / 8$, and $6 / 7$ animals in the vehicle control, $1 \mathrm{mg} / \mathrm{kg}, 10 \mathrm{mg} / \mathrm{kg}$ and $50 \mathrm{mg} / \mathrm{kg}$ anti-GPC1mAb groups, respectively. B, Anti-GPC1 mAb plasma levels on the final day of the experiment determined by ELICA showed a dose-dependent increase in the anti-GPC1 mAb plasma levels. Data are presented as mean $\pm \mathrm{SD}$ ( $\mathrm{N}=6$ for each study group). SD is denoted by the error bars. ${ }^{*} p<0.05$ and ${ }^{*} \mathrm{p} p<0.01$ compared among vehicle control, 1,10 and $50 \mathrm{mg} / \mathrm{kg}$ anti-GPC1 mAb groups using one-way ANOVA followed by Tukey-Kramer post hoc multiple comparison test. C, No significant difference in total lung weights that reflect the lung tumor burden was found among the four study groups using one-way ANOVA followed by Tukey-Kramer post hoc multiple comparison test $(p>0.05)$. Data are presented as mean \pm SD. SD is denoted by the error bars.

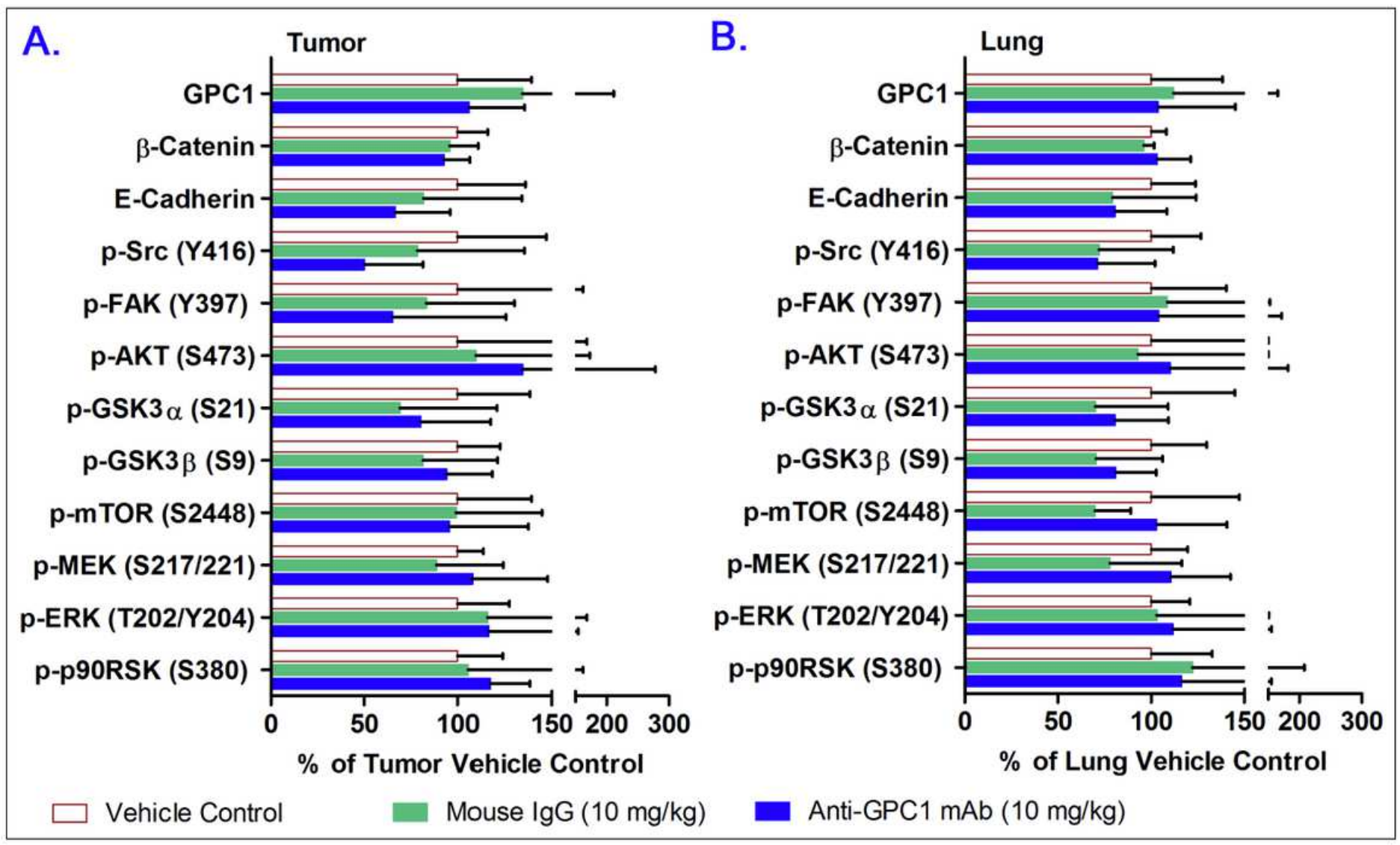

Figure 7

Densitometric analysis of Western blot results demonstrating the effect of anti-GPC1 mAb on the expression levels of selected EMT markers and effectors proteins common to the GPC1-facilitated signaling transduction, including MEK/ERK/RSK, AKT/GSK3/mTOR, Src/FAK signaling pathways in paired (A) A549 lung tumor xenografts and (B) adjacent noncancerous lung tissue samples. Tumor and adjacent normal lung tissue samples were collected from athymic nude mice bearing established 
orthotopic A549 lung tumor and receiving IV administration of vehicle control $(\mathrm{N}=5), 10 \mathrm{mg} / \mathrm{kg}$ mouse $\lg \mathrm{G}$ isotype $(\mathrm{N}=7)$, and $10 \mathrm{mg} / \mathrm{kg}$ anti-GPC1 $\mathrm{mAb}(\mathrm{N}=6)$ once every 72 hours for a total of 8 doses. Tumor and lung tissue homogenate samples were subjected to Western blot analysis ( $80 \mu \mathrm{g}$ of protein per lane). Detection of $\beta$-actin was used to ensure equal sample loading per lane. Relative immunoreactive band intensities are expressed as percent change over the average signal value in the vehicle-treated lung or tumor tissues. For phosphorylated proteins, results are expressed as the ratio of phosphorylated-to-total species relative to the vehicle control. Data are presented as mean $\pm S D$. SD is denoted by the error bars. No statistically significant difference was found among the three study groups $(p>0.05)$. 


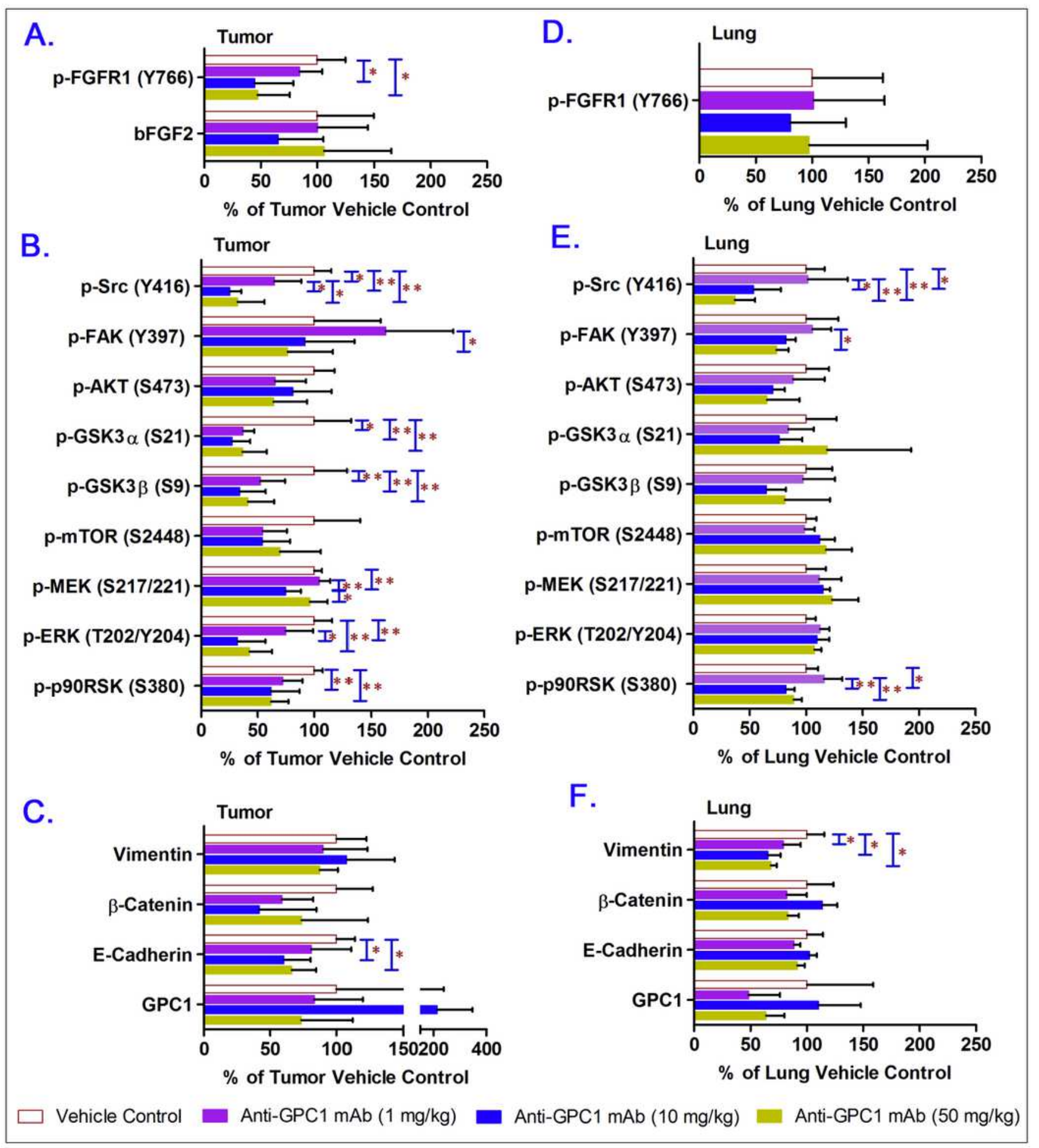

Figure 8

Densitometric analysis of Western blot results demonstrating the effect of anti-GPC1 mAb on the expression levels of selected EMT markers, GPC1-facilitated FGF2 activated FGFR1 downstream signaling pathways in paired $A 549$ lung tumor xenografts (A - C) and adjacent normal lung tissue samples (D - F). Athymic nude mice received IP administration of vehicle control, 1, 10 or $50 \mathrm{mg} / \mathrm{kg}$ of anti-GPC1 mAb two week after the orthotopic inoculation of A549 tumor cells. Each treatment was given 
to individual animals once a week for 3 doses and then once every 10 days for 2 more doses for a total of 8 doses. Tumor and lung tissue homogenate samples were subjected to Western blot analysis ( $80 \mu \mathrm{g}$ of protein per lane). Detection of $\beta$-actin was used to ensure equal sample loading per lane. Relative immunoreactive band intensities are expressed as percent change over the average signal value in the vehicle-treated lung or tumor tissues. For phosphorylated proteins, results are expressed as the ratio of phosphorylated-to-total species relative to the vehicle control. Data are presented as mean $\pm S D(N=6$ for each study group). SD is denoted by the error bars. ${ }^{*} p<0.05$ and ${ }^{* *} p<0.01$ compared among vehicle control, 1, 10 and $50 \mathrm{mg} / \mathrm{kg}$ anti-GPC1 mAb groups using one-way ANOVA followed by Tukey-Kramer post hoc multiple comparison test.

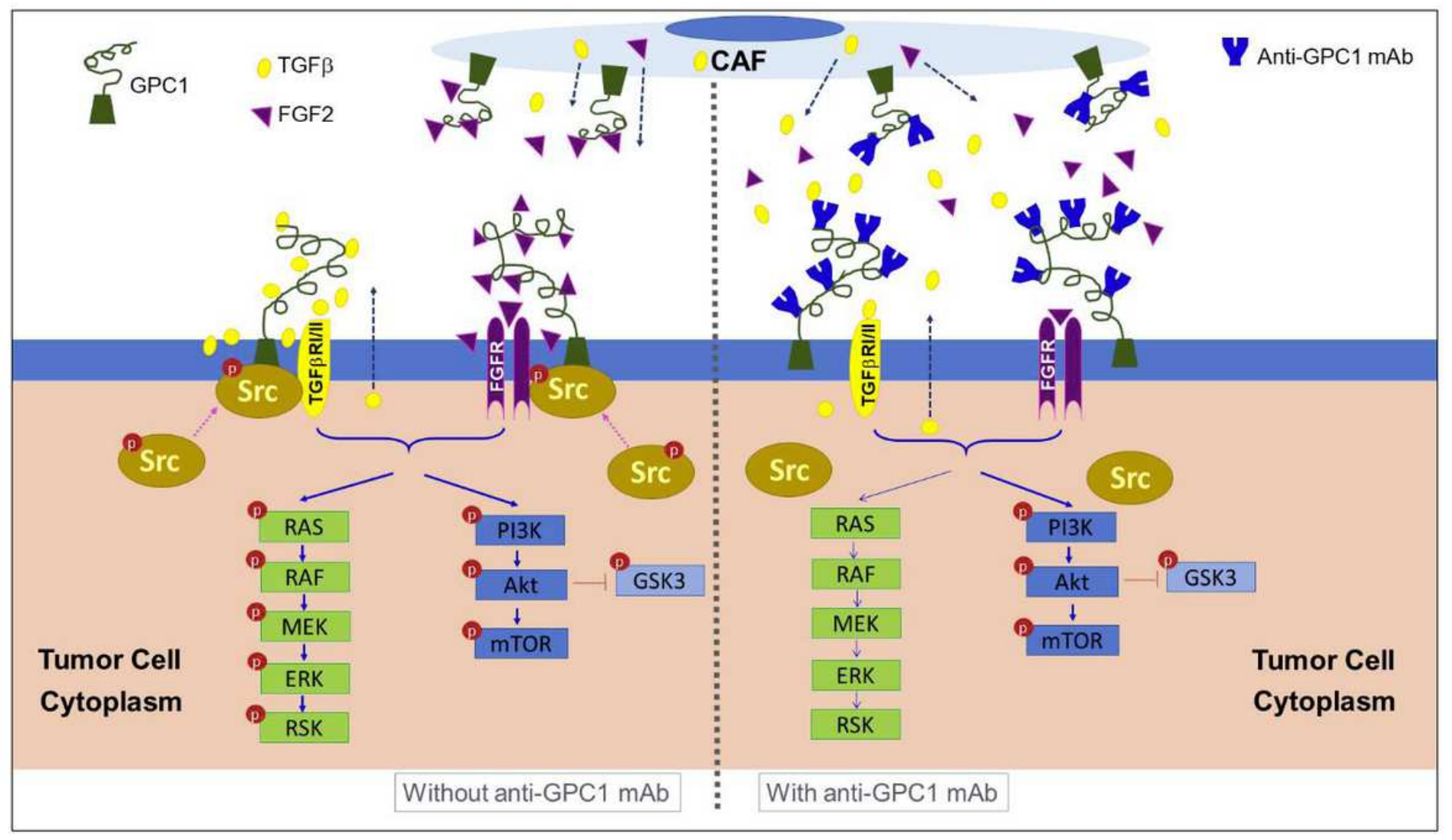

\section{Figure 9}

Schematic presentation of the proposed mechanism by which anti-GPC1 mAb impairs the GPC1facilitated encounter of growth factors with receptors that requires the Y416 phosphorylation of Src and recruitment of active Src onto the plasma membrane to initiate the signal transduction, leading to the attenuation of downstream MEK/ERK/RSK signaling pathway.

\section{Supplementary Files}

This is a list of supplementary files associated with this preprint. Click to download.

- SupplementarydataGPC1StudybyZhouCao.pdf 